\title{
Cooperative carbon emission reduction through the Belt and Road Initiative
}

\author{
Xiangyu Mao ${ }^{1} \cdot$ Ying Wang ${ }^{1}$ \\ Received: 14 June 2021 / Accepted: 19 August 2021 / Published online: 12 September 2021 \\ (C) The Author(s), under exclusive licence to Springer-Verlag GmbH Germany, part of Springer Nature 2021
}

\begin{abstract}
Carbon emission reduction under the Belt and Road Initiative has great significance on China's goal of carbon peak. To better promote carbon emission reduction, based on the background of the Belt and Road Initiative, this paper analyzes the collaborative carbon emission reduction through investment between Chinese enterprises and local enterprises in developing countries along the Belt and Road Initiative. Considering the efforts of enterprises in carbon reduction, low-carbon infrastructure investment, and promotion of low-carbon products, this paper constructs a differential game model of collaborative carbon reduction cooperation between Chinese enterprises and local enterprises in developing countries along the Belt and Road Initiative. By horizontally comparing Nash non-cooperative mode, Stackelberg master-slave mode, and cooperative mode, the results shows that Chinese enterprises can encourage local enterprises in developing countries along the Belt and Road Initiative to coordinate carbon emission reduction through subsidies, which is Stackelberg master-slave mode. Under the cooperative mode, with the maximum carbon emission reduction efforts of both parties, the total benefit of carbon emission reduction reaches the optimal Pareto equilibrium. In addition, this paper also discusses the influence of related factors on the benefits of carbon emission reduction.
\end{abstract}

Keywords Carbon emission reduction - The Belt and Road Initiative $\cdot$ Differential game $\cdot$ Parametric simulation $\cdot$ Optimal cooperation mode $\cdot$ Influencing factor

\section{Introduction}

In view of the increasingly serious global warming problem, carbon emission reduction has become a worldwide issue (Han et al. 2020). Governments of all countries are actively working to make efforts to reduce global carbon emissions. According to the latest data from the International Energy Agency (IEA), global carbon dioxide emissions have fallen by $5.8 \%$ in 2020 . But this decline is largely due to the COVID-19 pandemic that has slowed global economic activity. For this reason, the IEA predicts that global carbon emissions will continue to rise in 2021. Therefore, countries all

\section{Responsible Editor: Philippe Garrigues}

Xiangyu Mao

maoxiangyu@nuaa.edu.cn

Ying Wang

yingwang@nuaa.edu.cn

1 College of Economics and Management, Nanjing University of Aeronautics and Astronautics, Nanjing, China over the world must make more efforts to reduce carbon emissions in order to protect global environment.

With the development of the economy, China's carbon emissions are also increasing. Since 2008, China has been considered as the world's largest carbon emitter (Wu et al. 2019). Therefore, China should make more contributions to global carbon emission reduction efforts (Li et al. 2016). Because of these, China promised in its latest government work report that China's carbon dioxide emissions will no longer increase before 2030, and will gradually decrease after reaching a peak. Therefore, how to achieve this goal quickly has become an urgent problem that needs to be solved at present. China proposed the Belt and Road Initiative (BRI) in 2013, with the goal of establishing a mutually beneficial and win-win cooperation network with countries along the route (Liu et al. 2020). With the support of the Belt and Road Initiative, Chinese enterprises began to seek opportunities to invest in countries along the Belt and Road Initiative. According to the latest data released by the Ministry of Commerce of China, Chinese foreign non-financial direct investment in countries along the Belt and Road Initiative increased by $18.3 \%$ in 2020 , accounting for $16.2 \%$ of the total 
amount in the same period. Related research also pointed out that China and countries along the Belt and Road Initiative have great potential for cooperation (Liu and Hao 2018). Therefore, whether China can use the Belt and Road Initiative to speed up its own carbon emission reduction process through cooperation with countries along the route has important research value. In practice, many scholars have conducted research on China's carbon emission reduction through the Belt and Road Initiative. Chen et al. (2021) pointed out that China's OFDI has a positive impact on carbon emission reduction in countries along the Belt and Road Initiative. Rauf et al. (2018) had the same view. They measured indicators for 47 countries along the Belt and Road Initiative and found a negative correlation between trade openness and carbon emissions. Fan et al. (2019) indicated that technological innovation can curb carbon emissions. However, these studies have pointed out that investment activities under the Belt and Road Initiative can have a huge impact on countries' carbon reduction efforts, most of the existing studies have studied the carbon emission reduction under the Belt and Road Initiative through the calculation of indicators, and few studies studied the cooperation mode of carbon emission reduction under the Belt and Road Initiative from the macro level. Moreover, since most of the countries along the Belt and Road Initiative are developing countries, which capital and technology are not as well as China, then how China will cooperate with these countries in carbon emission reduction is worth studying. Therefore, the purpose of this paper is to discover the optimal mode for carbon emission reduction cooperation between China and the developing countries along the Belt and Road Initiative.

Based on comprehensive consideration of the carbon emission reduction investment and related subsidies of Chinese enterprises under the Belt and Road Initiative, this study analyzes the optimal carbon emission reduction strategies of Chinese enterprises and local enterprises in developing countries along the Belt and Road Initiative. By horizontally comparing the three modes of Nash non-cooperative mode, Stackelberg master-slave mode, and collaborative cooperation mode, this study explores the optimal cooperation mode for carbon emission reduction between Chinese enterprises and local enterprises in developing countries along the Belt and Road Initiative. Among them, it is assumed that Chinese enterprises and local enterprises in developing countries along the Belt and Road Initiative are mainly responsible for the investment in reducing carbon emissions in their cooperation to reduce carbon emissions. Local enterprises in developing countries along the Belt and Road Initiative are mainly responsible for the promotion of low-carbon products, and the two sides have made joint efforts to reduce carbon emissions. In addition, in order to encourage local enterprises in developing countries along the Belt and Road Initiative to reduce carbon emissions, Chinese enterprises will give them certain production and promotion subsidies. Specific process is shown in Fig. 1.

According to the description of the research content in Fig. 1 , we summarize the contributions of this paper. Firstly, this is the pioneer study to analyze the optimal cooperation mode of carbon emission reduction cooperation under the Belt and Road Initiative. Previous studies on carbon emission reduction under the Belt and Road Initiative mainly analyzed the impact of various influencing factors such as trade, investment, and energy on carbon emission reduction cooperation through the measurement of indicators, but few studies analyzed the cooperation mode of carbon emission reduction from a macro perspective. The study aims to analyze the competitive and cooperative relationship between China and developing countries along the Belt and Road Initiative through the game model and explore the optimal mode of carbon emission reduction cooperation under the Belt and Road Initiative.

Secondly, a significant contribution of this study is the application of differential game model in the research of carbon emission reduction cooperation under the Belt and Road Initiative. Since carbon emission reduction cannot be achieved overnight, it often takes a long time to succeed. Therefore, the differential game model which is considered the time factor can describe this problem well. Through differential game model, this study analyzes how the degree of efforts made by Chinese enterprises and local enterprises in developing countries along the Belt and Road Initiative in carbon emission reduction affect the final carbon emission reduction effect. And this has great significance for Chinese enterprises to deepen carbon emission reduction cooperation with local enterprises of developing countries along the Belt and Road Initiative.

Thirdly, identifying the role of Chinese enterprises in cooperation of carbon emission reduction cooperation under the Belt and Road Initiative is another contribution of this study. Although existing studies have pointed out that Chinese enterprises should play an important role in the Belt and Road Initiative cooperation (Li et al. 2020; Zhen and Lin 2017; Cheng 2016), there is no clear indication of how to play this important role. This study clearly points out that Chinese enterprises should play a leading role in the current cooperation and encourage local enterprises in developing countries along the Belt and Road Initiative to participate in the carbon emission reduction cooperation through a series of incentives. After the capital and technical strength of the local enterprises have been improved, the two sides will carry out equal and mutually beneficial cooperation to realize the maximum benefits. And this study aims to provide significant policy suggestions for policymakers of enterprises and government to better carry out carbon emission reduction cooperation under the Belt and Road Initiative. 


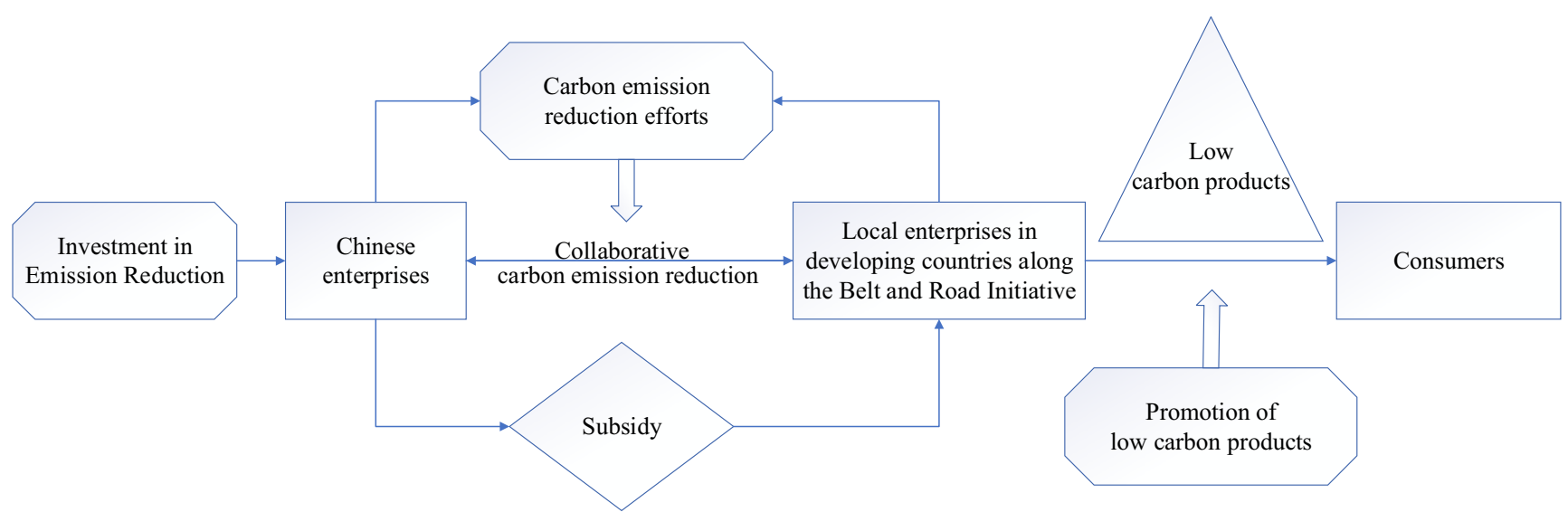

Fig. 1 Decision-making process of carbon emission reduction under the Belt and Road Initiative

In order to realize the above research contributions, this study addressed the following five questions:(1) How does the degree of efforts made by Chinese enterprises and local enterprises in developing countries along the Belt and Road Initiative in carbon emission reduction affect the final carbon emission reduction effect? (2) What is the impact of the carbon emission reduction subsidies provided by Chinese enterprises to local enterprises in developing countries along the Belt and Road Initiative on the effect of carbon emission reduction? (3) What is the impact of other factors on cooperative carbon emission reduction? (4) What is the optimal cooperation mode for carbon emission reduction between China and the developing countries along the Belt and Road Initiative? (5) How to formulate relevant policies to promote collaborative carbon emission reduction under the Belt and Road Initiative?

The remainder of this paper is organized as follows: the "Literature review" section reviews the relevant literature and introduces the main contribution of this study. The "Model assumptions and symbols" section details the basic assumptions and relevant parameters of the differential game model. The "Modeling and analysis" section constructs a carbon emission reduction model under the Belt and Road Initiative and analyzes the results under three different situations. The "Analysis of examples" section verifies the correctness of the research conclusions through parameter assignment and software simulation. The "Conclusions and policy implications" section summarizes the relevant conclusions and implications.

\section{Literature review}

In this section, three main literature streams are mainly reviewed: (1) cooperation mode under the Belt and Road Initiative, (2) carbon emission reduction under the Belt and Road Initiative, and (3) application of game model in carbon emission reduction research.

\section{Cooperation mode under the Belt and Road Initiative strategy}

The Belt and Road Initiative is China's top-level cooperation strategy, which has exerted great influence on energy, trade, and infrastructure construction of countries along the route since its implementation. With the deepening of the Belt and Road Initiative, what is the best mode of cooperation between countries, and how the participating countries can cooperate to get the maximum benefit has become an urgent problem to be solved.

Most of the existing literatures believe that the cooperation mode under the Belt and Road Initiative should be equal and mutually beneficial. For instance, Khan et al. (2018) believed that the cooperation mode under the Belt and Road Initiative should be an inclusive and open "win-win" cooperation mode based on shared development and shared future. Andornino (2017) pointed out that the Belt and Road Initiative strategy can integrate the existing order and create a non-hegemonic international capital. Zhao et al. (2019) took energy cooperation as an example and pointed out that the cooperation between China and countries along the Belt and Road Initiative should be interdependent. Yang et al. (2021) took the case of China-Myanmar energy cooperation and claimed that the cooperation mode under the Belt and Road Initiative should be equal and mutually beneficial.

Yilmaz and Changming (2020) argued that the cooperation between China and Russia under the Belt and Road Initiative should establish a strategic cooperative partnership based on exploring the actual and potential similarities and differences between the two countries.

In addition, some studies believed that China should play the role of helper in the Belt and Road Initiative's cooperation. Qian et al. (2019) cited the case of cooperation between China and Mongolia in the prevention and treatment of echinococcosis and thought that only by adopting the public health cooperation mode of "Mongolia-led, China-supported and results-sharing" can Mongolia and China achieve win-win 
cooperation. Liu et al. (2021a) used Singapore's successful case in the Belt and Road Initiative to illustrate that small countries can also have autonomy in cooperation with big countries.

Actually, with the enhancement of national strength, China is playing an increasingly important role in international affairs (Varrall 2013). Therefore, some scholars have suggested that China should play an important role in the Belt and Road Initiative's trade pattern (Li et al. 2020; Zhen and Lin 2017; Cheng 2016). However, these studies only pointed out that China should play an important role in the Belt and Road Initiative cooperation but did not prove this view from the theoretical basis. In addition, the above-mentioned documents did not determine the optimal mode through horizontal comparison of various cooperation modes. Therefore, based on the differential game model, this paper compares the cooperative benefits of the Belt and Road Initiative's carbon emission reduction in Nash non-cooperative form, Stackelberg master-slave form, and cooperative form horizontally and finally determines the optimal cooperation mode.

\section{Carbon emission reduction strategies under different scenarios}

With rapid economic growth and urbanization, carbon emissions will naturally increase (Sarwar and Alsaggaf 2019). However, excessive carbon emissions will have a huge impact on economic development and public health (Sarwar et al. 2019). Therefore, relevant scholars have proposed some ways to reduce carbon emissions. For example, Sarwar (2019) used data from 30 Chinese provinces to show that building industrial carbon treatment plants would help control the sharp rise in carbon emissions; Farooq et al. (2019) used regression analysis to show that reforestation could reduce the health impact of carbon emissions; Anwar et al. (2019) argued that using clean energy such as nuclear power can help reduce carbon dioxide emissions; Sarwar and Alsaggaf (2021) used Saudi Arabia's successful case in carbon emission reduction to illustrate that the governance efficiency and regulatory quality of the government have a direct positive relationship with the effect of carbon emission reduction. However, these studies have put forward relevant suggestions on carbon emission reduction from different perspectives, but most of them are focused on the carbon emission reduction of one country, and few of them study the joint carbon emission reduction among countries, which cannot fundamentally solve the problem of high carbon emissions on a global scale. Therefore, how to carry out cooperation among countries to reduce carbon emissions has become an urgent problem to be solved. And as a joint development strategy among countries, whether the Belt and Road Initiative (BRI) can be used in the carbon emission reduction cooperation between countries has great research value.
After the Belt and Road Initiative (BRI) has become an important foreign trade policy of China, many scholars have studied the impact of the Belt and Road Initiative on carbon emissions in countries along the route. In this part of the study, scholars have two completely different views. First view is that the Belt and Road Initiative will transfer China's highcarbon emission industry and cause great damage to the environment of countries along the route (Han et al. 2018). Second view is that the Belt and Road Initiative will make China and other countries along the route mutually beneficial and winwin and jointly reduce carbon emissions (Wu et al., n.d.).

In the first view, Fan et al. (2019) through the survey found that the total carbon emissions of the B\&R countries increased and $70 \%$ of these countries increased at a relatively high rate. Mahadevan and Sun (2020) pointed out that China may export carbon emissions via its FDI in the Belt and Road Initiative. $\mathrm{Wu}$ et al. (2019) measured the data of 65 countries along the Belt and Road Initiative and found that these countries have increased their carbon emissions as well as their economic growth.

In the second view, Rauf et al. (2018) argued that energy consumption, economic growth, financial development, and urbanization adversely lead to environmental degradation (CO2 emission) rather than trade openness. Zhang et al. (2020) investigated the energy performance of countries along the Belt and Road Initiative. They pointed out that these countries have great potential for cooperation in carbon emission reduction and the Belt and Road Initiative can help them carry out deep cooperation in carbon emission reduction. Qi et al. (2019) believed that China has launched a green BRI to improve the energy efficiency of countries along the route. Tao et al. (2020) considered that although the Belt and Road Initiative has increased its carbon emissions in a short time, in the long run, the Belt and Road Initiative will have a positive impact on the carbon emission reduction work of countries along the route. Meanwhile, the problem of carbon emission inequality in the Belt and Road Initiative has been studied by some scholars. Han et al. (2020) analyzed the inequality of carbon emissions in the Belt and Road Initiative and found that the level of carbon emission inequality in the Belt and Road Initiative is lower than the direct average. Han et al. (2020) analyzed the data and believed that the level of carbon emission inequality in countries along the Belt and Road Initiative is lower than the world average. The above research shows that there is no problem of carbon emission inequality in the Belt and Road Initiative and China and countries along the route can achieve mutual benefit and win-win through the Belt and Road Initiative and jointly carry out carbon emission reduction work.

In response to this controversial issue, some scholars have proposed solutions to solve it. For example, Muhammad et al. (2020) suggested that strengthening the disclosure of environmental information of foreign direct investment enterprises 
can reduce carbon emissions. Dargusch (2017) claimed that in the follow-up development of the Belt and Road Initiative, advanced green energy technologies and low-carbon incentives should play a key role. Wu et al. (2019) indicated that reliable financial assistance and technology transfer will enable China and countries along the Belt and Road Initiative to better carry out carbon emission reduction work. But carbon emission reduction is a dynamic process (Ma et al. 2020; $\mathrm{Li}$ et al. 2019; Sun et al. 2020), and China and developing countries along the Belt and Road Initiative should jointly carry out carbon emission reduction work for a sustained period. Existing literature are based on static point of view and rarely focuses on this aspect. Therefore, this paper uses the differential game model, which is especially suitable to study the carbon emissions of China and developing countries along the Belt and Road Initiative from a dynamic perspective, in order to find an optimal cooperation mode to jointly reduce carbon emissions.

\section{Application of game model in carbon emission reduction research}

Due to the work of carbon emission reduction is full of conflicts and cooperation, the game theory has been widely applied to the research of carbon emission reduction. Liu et al. (2021b) used bilateral matching game to study the investment of low-carbon emission reduction technology under carbon trading. Haque et al. (2020) used Nash game to study the information sharing of decentralized supply chain in carbon emission reduction. Ding et al. (2020) studied the influence of national carbon tax legislation on enterprise production decision with game model. Based on game model, Qin et al. (2020) studied the value chain of prepayment financing for carbon emission reduction and production supply. Shan et al. (2019) analyzed the role of industrial symbiosis system in promoting carbon emission reduction with evolutionary game model.

Since carbon emission reduction cannot be achieved overnight, it often takes a long time to succeed. Therefore, the differential game model which considers the time factor can describe this problem well. Xia et al. (2020) used differential game model to study the carbon emission reduction of supply chain considering social preference factors and found that the carbon emission reduction of supply chain can be improved by Pareto improvement through cost-sharing contract. $\mathrm{Zu}$ et al. (2018) used differential game model to study the collaborative carbon emission reduction between manufacturers and suppliers. The result shows that only by establishing a coordination mechanism can suppliers make more efforts. Wang et al. (2019) found that the carbon tax policy has a positive impact on the strategy and performance of lowcarbon technology sharing among enterprises by using the differential game model. Therefore, it is reasonable for this paper to use differential game model to study the collaborative carbon emission reduction between Chinese enterprises and local enterprises in developing countries along the Belt and Road Initiative.

Based on the above analysis, this article provides the following contributions: (1) this article discusses the optimal cooperation mode under the Belt and Road Initiative: collaborative cooperation between China and developing countries along the Belt and Road Initiative is the best mode, but under the existing cooperation mode, China-led cooperation is the most effective. (2) A comprehensive analysis of carbon emission conduction under the Belt and Road Initiative is conducted based on differential game model. Previous studies have some differences on the impact of the Belt and Road Initiative on carbon emission reduction, but no conclusion has been drawn. This paper thinks that the Belt and Road Initiative in China has a positive impact on the carbon emission reduction of countries along the route and, on this basis, puts forward relevant countermeasures to promote the carbon emission reduction of the Belt and Road Initiative according to the game theory model.

\section{Model assumptions and symbols}

Considering the various influencing factors of carbon emission reduction under the Belt and Road Initiative, this paper constructs a differential game model including Chinese enterprises and local enterprises in developing countries along the Belt and Road Initiative, and the following basic assumptions have been made:

(1) $C_{F}$ and $C_{L}$ respectively represent the emission reduction costs of Chinese enterprises and local enterprises in developing countries along the Belt and Road Initiative at $t$, which are the increasing function of their respective efforts $E_{F}(t)$ and $E_{L}(t)$, and have convex characteristics, so they are expressed in quadratic form. That is, $C_{F}^{\prime}$ $\left(E_{F}(t)\right)>0, C_{F}^{\prime \prime}\left(E_{F}(t)\right)>0, C_{L}^{\prime}\left(E_{L}(t)\right)>0$ and $C_{L}^{\prime \prime}\left(E_{L}(t)\right)>0$ are satisfied, so it can be assumed that the cost of carbon emission reduction is:

$$
\begin{aligned}
& C_{F}^{\prime}\left(E_{F}(t)\right)=\frac{1}{2} k_{F} E_{F}^{2}(t) \\
& C_{L}^{\prime}\left(E_{L}(t)\right)=\frac{1}{2} k_{L} E_{L}^{2}(t)
\end{aligned}
$$

Among them, $k_{F}$ and $k_{L}$ respectively represent the carbon emission reduction cost coefficients of Chinese enterprises and local enterprises in developing countries along the Belt and Road Initiative. 
(2) The cost of publicity and promotion of local enterprises in developing countries along the Belt and Road Initiative is the increasing function of low-carbon publicity and promotion efforts $E_{R}(t)$ and has convex characteristics, so it is expressed in quadratic form. That is, $C_{R}^{\prime}\left(E_{R}(t)\right)>0$ and $C_{R}^{\prime \prime}\left(E_{R}(t)\right)>0$ are satisfied, so it can be assumed that the cost of publicity and promotion of low-carbon products is:

$C_{R}^{\prime}\left(E_{R}(t)\right)=\frac{1}{2} k_{R} E_{R}^{2}(t)$

Among them, $k_{R}$ represents the cost coefficient of publicity and promotion of local enterprises in developing countries along the Belt and Road Initiative.

(3) The emission reduction investment cost of Chinese enterprises is the increasing function of emission reduction investment effort $E_{I}(t)$, and it has convex characteristics, so it is expressed in quadratic form. That is, $C_{I}^{\prime}\left(E_{I}(t)\right)>$ 0 and $C_{I}^{\prime \prime}\left(E_{I}(t)\right)>0$ are satisfied, so it can be assumed that the investment cost of emission reduction of lowcarbon products is:

$C_{I}^{\prime}\left(E_{I}(t)\right)=\frac{1}{2} k_{I} E_{I}^{2}(t)$

Among them, $k_{I}$ represents the investment cost coefficient of emission reduction of Chinese enterprises.

(4) Suppose $H_{A}(t)$ indicates the carbon emission reduction of the final product at time $t$, which is determined by the efforts of Chinese enterprises and local enterprises in developing countries along the Belt and Road Initiative, and it is a dynamic change process. Therefore, the following differential equation can be used to describe the change law of carbon emission reduction of the final product with time:

$\left\{\begin{array}{c}H_{A}^{\prime}(t)=\frac{d H_{A}(t)}{d t}=\alpha_{F} E_{F}(t)+\alpha_{L} E_{L}(t)-\delta H_{A}(t) \\ H_{A}(0)=H_{A} \geq 0\end{array}\right.$

(5) Suppose $H_{B}(t)$ indicates the local influence of the final product in the host country at time $t$, which is determined by the publicity and promotion efforts of local enterprises in developing countries along the Belt and Road Initiative and the emission reduction investment efforts of Chinese enterprises and is a dynamic change process. Therefore, the following differential equation can be used to describe the change law of the influence of the final product in the host country with time:

$$
\left\{\begin{array}{c}
H_{B}^{\prime}(t)=\frac{d H_{B}(t)}{d t}=\beta_{F} E_{I}(t)+\beta_{R} E_{R}(t)-\theta H_{B}(t) \\
H_{B}(0)=H_{B} \geq 0
\end{array}\right.
$$

Among them, $\beta_{F}$ represents the impact coefficient of the efforts made by Chinese enterprises on the local influence of the final products in the host country; $\beta_{R}$ represents the influence coefficient of the efforts made by local enterprises in developing countries along the Belt and Road Initiative on the local influence of the final products in the host country; $\theta>0$ represents the attenuation degree of the local influence of the final product in the host country, which means that with the continuous expansion of carbon emission reduction investment and publicity and promotion efforts, the growth rate of $H_{B}(t)$ will continue to decline, that is, the marginal utility will decrease; $H_{B}(0)$ represents the initial state of the local influence of the final product in the host country.

(6) The efforts of Chinese enterprises and local enterprises in developing countries along the Belt and Road Initiative in their respective carbon emission reduction costs will directly affect the carbon emission reduction benefits of the whole system. At the same time, the carbon emission reduction of the final product can also benefit the whole system by improving the core competitiveness of the final product of the whole Belt and Road Initiative system. The local influence of the final product in the host country can also influence the core competitiveness of the final product and make the whole system gain profits. Therefore, considering the combined influence of carbon emission reduction cost, carbon emission reduction of the final product, and the local influence of the final product in the host country, it is assumed that the total benefit $\pi(t)$ of carbon emission reduction under the Belt and Road Initiative embedding is:

$\pi(t)=\gamma_{F} E_{F}(t)+\gamma_{L} E_{L}(t)+\omega \mathrm{H}_{A}(t)+\eta H_{B}(t)$

Among them, $\gamma_{F}$ and $\gamma_{L}$ respectively indicate the impact of the efforts made by Chinese enterprises and local enterprises in developing countries along the Belt and Road Initiative on the total income; $\omega$ indicates the degree of influence of the carbon emission reduction of the final product on the total income of the Belt and Road Initiative; $\eta$ indicates the influence of the local influence of the final product in the host country on the total income of the Belt and Road Initiative.

(7) It is assumed that under the Belt and Road Initiative, the total income from carbon emission reduction is distributed between Chinese enterprises and local enterprises along the Belt and Road Initiative according to a certain distribution ratio. Local enterprises along the Belt and Road Initiative countries get $\mu$, while Chinese enterprises 
get $1-\mu$. Among them, $0 \leq \mu \leq 1$ is the income distribution coefficient, which is determined by the contribution made by the countries participating in the Belt and Road Initiative to carbon emission reduction and the right to speak in the system.

(8) In order to encourage local enterprises in developing countries along the Belt and Road Initiative to make more efforts in carbon emission reduction, Chinese enterprises will share part of the carbon emission reduction costs and publicity and promotion costs. Among them, 0 $\leq \lambda_{L}(t) \leq 1$ is the proportion of carbon emission reduction costs shared by Chinese enterprises; $0 \leq \lambda_{R}(t) \leq 1$ is the proportion of publicity and promotion costs shared by Chinese foreign investment enterprises.

(9) Assume that both Chinese enterprises and local enterprises in developing countries along the Belt and Road Initiative are rational decision makers, have complete information, have the same discount rate $\rho(\rho>0)$ at any time, and aim to maximize their own income in an infinite time.

According to the above assumptions, the objective function of local enterprises in developing countries along the Belt and Road Initiative can be obtained:

$$
\begin{gathered}
\Pi_{L}=\int_{0}^{\infty} e^{-\rho t}\left[\mu\left(\gamma_{F} E_{F}(t)+\gamma_{L} E_{L}(t)+\omega H_{A}(t)+\eta H_{B}(t)\right)\right. \\
\left.-\frac{1}{2}\left(1-\lambda_{L}\right) k_{L} E_{L}^{2}(t)-\frac{1}{2}\left(1-\lambda_{R}\right) k_{R} E_{R}^{2}(t)\right] d t
\end{gathered}
$$

Objective function of Chinese enterprises can be obtained:
Belt and Road Initiative, that is, $\lambda_{L}=\lambda_{R}=0$, both parties make optimal decisions at the same time, and the strategic combination constitutes Nash equilibrium solution. Currently, the objective functions of both parties are:

$$
\Pi_{L}=\int_{0}^{\infty} e^{-\rho t}\left[\mu\left(\gamma_{F} E_{F}+\gamma_{L} E_{L}+\omega H_{A}+\eta H_{B}\right)-\frac{1}{2} k_{L} E_{L}^{2}-\frac{1}{2} k_{R} E_{R}^{2}\right] d t
$$

$\Pi_{F}=\int_{0}^{\infty} e^{-\rho t}\left[(1-\mu)\left(\gamma_{F} E_{F}+\gamma_{L} E_{L}+\omega H_{A}+\eta H_{B}\right)-\frac{1}{2} k_{F} E_{F}^{2}-\frac{1}{2} k_{I} E_{I}^{2}\right] d t$

Proposition 1 In the Nash non-cooperative game, the best strategies of Chinese enterprises and local enterprises in developing countries along the Belt and Road Initiative are as follows:

$$
\begin{aligned}
\left(E_{L}^{N}, E_{R}^{N}\right) & =\left(\frac{\mu\left[\gamma_{L}(\rho+\delta)+\alpha_{L} \omega\right]}{k_{L}(\rho+\delta)}, \frac{\mu \eta \beta_{R}}{k_{R}(\rho+\theta)}\right) \\
\left(E_{F}^{N}, E_{I}^{N}\right) & =\left(\frac{(1-\mu)\left[\gamma_{F}(\rho+\delta)+\alpha_{F} \omega\right]}{k_{F}(\rho+\delta)}, \frac{(1-\mu) \eta \beta_{F}}{k_{I}(\rho+\theta)}\right)
\end{aligned}
$$

The optimal return functions $V_{L}\left(H_{A}, H_{B}\right)$ and $V_{F}\left(H_{A}, H_{B}\right)$ of local enterprises and Chinese enterprises along the Belt and Road Initiative are:

$$
\begin{gathered}
V_{L}^{N}=\frac{\mu \omega}{\rho+\delta} H_{A}^{\mathrm{N}}+\frac{\mu \eta}{\rho+\theta} H_{B}^{N}+\frac{\mu^{2}\left[\gamma_{L}(\rho+\delta)+\alpha_{L} \omega\right]^{2}}{2 \rho k_{L}(\rho+\delta)^{2}}+\frac{\left(\mu \eta \beta_{R}\right)^{2}}{2 \rho k_{R}(\rho+\theta)^{2}} \\
+\frac{\mu(1-\mu)\left[\gamma_{F}(\rho+\delta)+\alpha_{F} \omega\right]^{2}}{\rho k_{F}(\rho+\delta)^{2}}+\frac{\mu(1-\mu)\left(\eta \beta_{F}\right)^{2}}{\rho k_{I}(\rho+\theta)^{2}} \\
V_{F}^{N}=\frac{(1-\mu) \omega}{\rho+\delta} H_{A}^{N}+\frac{(1-\mu) \eta}{\rho+\theta} H_{B}^{N}+\frac{(1-\mu)^{2}\left[\gamma_{F}(\rho+\delta)+\alpha_{F} \omega\right]^{2}}{2 \rho k_{F}(\rho+\delta)^{2}}+\frac{\left[(1-\mu)\left(\eta \beta_{R}\right)\right]^{2}}{2 \rho k_{I}(\rho+\theta)^{2}} \\
+\frac{\mu(1-\mu)\left[\gamma_{L}(\rho+\delta)+\alpha_{L} \omega\right]^{2}}{\rho k_{L}(\rho+\delta)^{2}}+\frac{\mu(1-\mu)\left(\eta \beta_{R}\right)^{2}}{\rho k_{R}(\rho+\theta)^{2}}
\end{gathered}
$$

sion reduction under the Belt and Road Initiative. Through horizontal comparison of Nash noncooperative mode, Stackelberg master-slave mode, and cooperative mode, the optimal cooperation mode for carbon emission reduction under the Belt and Road Initiative is determined. The specific certification process is shown in the appendix.

\section{Nash non-cooperative game}

In this case, in order to maximize their own profits, Chinese enterprises will be unwilling to share any costs for the local enterprises in the host countries along the
Under this model, the optimal benefit function $V\left(H_{A}, H_{B}\right)$ of cooperative emission reduction between Chinese enterprises and local enterprises in developing countries along the Belt and Road Initiative is:

$$
\begin{aligned}
V^{N}= & \frac{\omega}{\rho+\delta} H_{A}^{N}+\frac{\eta}{\rho+\theta} H_{B}^{N}+\frac{\mu(2-\mu)\left[\gamma_{L}(\rho+\delta)+\alpha_{L} \omega\right]^{2}}{2 \rho k_{L}(\rho+\delta)^{2}}+\frac{\mu(2-\mu)\left(\eta \beta_{R}\right)^{2}}{2 \rho k_{R}(\rho+\theta)^{2}} \\
& +\frac{(1+\mu)(1-\mu)\left[\gamma_{\mathrm{F}}(\rho+\delta)+\alpha_{F} \omega\right]^{2}}{2 \rho k_{F}(\rho+\delta)^{2}}+\frac{(1+\mu)(1-\mu)\left(\eta \beta_{F}\right)^{2}}{2 \rho k_{I}(\rho+\theta)^{2}}
\end{aligned}
$$

The proof of this Proposition is given in Appendix 1 . 


\section{Stackelberg master-slave game}

In this case, in order to encourage local enterprises in developing countries along the Belt and Road Initiative to carry out carbon emission reduction, Chinese enterprises will bear a certain proportion of carbon emission reduction costs and low-carbon product promotion and promotion costs. Assuming that the subsidy coefficients are $\lambda_{L}(t)$ and $\lambda_{R}(t)$ respectively, the purpose is to encourage local enterprises in developing countries along the Belt and Road Initiative to carry out carbon emission reduction according to the wishes of Chinese enterprises. Therefore, the game process between Chinese enterprises as leaders and local enterprises in developing countries along the Belt and Road Initiative as followers can be regarded as Stackelberg master-slave game process, and both sides independently make the best strategy to maximize their own profits. The game is divided into two stages, in which Chinese enterprises first decide their strategy $\left(E_{F}, E_{I}\right)$ and subsidy ratios $\lambda_{L}$ and $\lambda_{R}$, and local enterprises in developing countries along the Belt and Road Initiative choose their own optimal strategy $\left(E_{L}, E_{R}\right)$ after observing the decision of Chinese enterprises. Currently, the objective functions of both parties are:

$$
\begin{gathered}
\Pi_{R}=\int_{0}^{\infty} e^{-\rho t}\left[\mu\left(\gamma_{F} E_{F}(t)+\gamma_{L} E_{L}(t)+\omega H_{A}(t)+\eta H_{B}(t)\right)\right. \\
\left.-\frac{1}{2}\left(1-\lambda_{L}\right) k_{L} E_{L}^{2}(t)-\frac{1}{2}\left(1-\lambda_{R}\right) k_{R} E_{R}^{2}(t)\right] d t
\end{gathered}
$$

$$
\begin{aligned}
\Pi_{F}= & \int_{0}^{\infty} e^{-\rho t}\left[(1-\mu)\left(\gamma_{F} E_{F}(t)+\gamma_{L} E_{L}(\mathrm{t})+w H_{A}(t)+\eta H_{B}(t)\right)-\frac{1}{2} k_{F} E_{F}^{2}(t)\right. \\
& \left.-\frac{1}{2} k_{I} E_{I}^{2}(t) \quad-\frac{1}{2} \lambda_{L} k_{L} E_{L}^{2}(t)-\frac{1}{2} \lambda_{R} k_{R} E_{R}^{2}(t)\right] d t
\end{aligned}
$$

Proposition 2 In Stackelberg master-slave game, the best strategies of Chinese enterprises and local enterprises in developing countries along the Belt and Road Initiative are as follows:

$$
\begin{aligned}
& \left(E_{L}^{S}, E_{R}^{S}\right)=\left(\frac{(2-\mu)\left[\gamma_{L}(\rho+\delta)+\alpha_{L} \omega\right]}{2 k_{L}(\rho+\delta)}, \frac{(2-\mu) \eta \beta_{R}}{2 k_{R}(\rho+\theta)}\right) \\
& \left(E_{F}^{S}, E_{I}^{S}\right)=\left(\frac{(1-\mu)\left[\gamma_{F}(\rho+\delta)+\alpha_{F} \omega\right]}{k_{F}(\rho+\delta)}, \frac{(1-\mu) \eta \beta_{F}}{k_{I}(\rho+\theta)}\right) \\
& \lambda_{L}^{S}=\frac{2-3 \mu}{2-\mu}, 0<\mu<\frac{2}{3} \\
& \lambda_{R}^{S}=\frac{2-3 \mu}{2-\mu}, 0<\mu<\frac{2}{3}
\end{aligned}
$$

The optimal return functions $V_{L}\left(H_{A}, H_{B}\right)$ and $V_{F}\left(H_{A}, H_{B}\right)$ of local enterprises and Chinese enterprises along the Belt and Road Initiative are:

$$
\begin{gathered}
V_{L}^{S}=\frac{\mu \omega}{\rho+\delta} H_{A}^{S}+\frac{\mu \eta}{\rho+\theta} H_{B}^{S}+\frac{\mu(1-\mu)\left[\gamma_{F}(\rho+\delta)+\alpha_{F} \omega\right]^{2}}{\rho k_{F}(\rho+\delta)^{2}}+\frac{\mu(1-\mu)\left(\eta \beta_{F}\right)^{2}}{\rho k_{I}(\rho+\theta)^{2}} \\
+\frac{\mu(2-\mu)\left[\gamma_{L}(\rho+\delta)+\alpha_{L} \omega\right]^{2}}{4 \rho k_{L}(\rho+\delta)^{2}}+\frac{\mu(2-\mu)\left(\eta \beta_{R}\right)^{2}}{4 \rho k_{R}(\rho+\theta)^{2}}
\end{gathered}
$$

$$
\begin{gathered}
V_{F}^{S}=\frac{(1-\mu) \omega}{\rho+\delta} H_{A}^{S}+\frac{(1-\mu) \eta}{\rho+\theta} H_{B}^{S}+\frac{(1-\mu)^{2}\left[\gamma_{F}(\rho+\delta)+\alpha_{F} \omega\right]^{2}}{2 \rho k_{F}(\rho+\delta)^{2}}+\frac{(1-\mu)^{2}\left(\eta \beta_{F}\right)^{2}}{2 \rho k_{I}(\rho+\theta)^{2}} \\
+\frac{(2-\mu)^{2}\left[\gamma_{L}(\rho+\delta)+\alpha_{L} \omega\right]^{2}}{8 \rho k_{L}(\rho+\delta)^{2}}+\frac{(2-\mu)^{2}\left(\eta \beta_{R}\right)^{2}}{8 \rho k_{R}(\rho+\theta)^{2}}
\end{gathered}
$$

Under this model, the optimal benefit function $V\left(H_{A}, H_{B}\right)$ of cooperative emission reduction between Chinese enterprises and local enterprises in developing countries along the Belt and Road Initiative is:

$$
\begin{aligned}
V^{S} & =\frac{\omega}{\rho+\delta} H_{A}^{S}+\frac{\eta}{\rho+\theta} H_{B}^{S}+\frac{(2+\mu)(2-\mu)\left[\gamma_{L}(\rho+\delta)+\alpha_{L} \omega\right]^{2}}{8 \rho k_{L}(\rho+\delta)^{2}} \\
& +\frac{(2+\mu)(2-\mu)\left(\eta \beta_{R}\right)^{2}}{8 \rho k_{R}(\rho+\theta)^{2}}+\frac{(1+\mu)(1-\mu)\left[\gamma_{F}(\rho+\delta)+\alpha_{F} \omega\right]^{2}}{2 \rho k_{F}(\rho+\delta)^{2}} \\
& +\frac{(1+\mu)(1-\mu)\left(\eta \beta_{F}\right)^{2}}{2 \rho k_{I}(\rho+\theta)^{2}}
\end{aligned}
$$

The proof of this Proposition is given in the Appendix 2 .

\section{Cooperative game}

In this case, Chinese enterprises and local enterprises in developing countries along the Belt and Road Initiative jointly improve the efficiency and quality of carbon emission reduction through cooperation. As an organic whole, both parties will take the maximization of overall benefits as the goal and jointly determine the optimal decision of both parties. At this point, the objective function of the system is:

$$
\begin{gathered}
I=\Pi_{L}+\Pi_{F}=\int_{0}^{\infty} e^{-\rho t}\left[\mu_{F}\left(\gamma_{F} E_{F}(t)+\gamma_{L} E_{L}(t)+w H_{A}(t)+\eta H_{B}(t)\right)-\frac{1}{2} k_{F} E_{F}^{2}(t)\right. \\
\left.-\frac{1}{2} k_{I} E_{I}^{2}(t)-\frac{1}{2} k_{L} E_{L}^{2}(t)-\frac{1}{2} k_{R} E_{R}^{2}(t)\right] d t
\end{gathered}
$$

Proposition 3 In the cooperative game between Chinese enterprises and local enterprises in developing countries along the Belt and Road Initiative, the optimal strategies of both parties are as follows:

$$
\begin{aligned}
& \left(E_{L}^{C}, E_{R}^{C}\right)=\left(\frac{\gamma_{L}(\rho+\delta)+\alpha_{L} \omega}{k_{L}(\rho+\delta)}, \frac{\eta \beta_{R}}{k_{R}(\rho+\theta)}\right) \\
& \left(E_{F}^{C}, E_{I}^{C}\right)=\left(\frac{\gamma_{F}(\rho+\delta)+\alpha_{F} \omega}{k_{F}(\rho+\delta)}, \frac{\eta \beta_{F}}{k_{I}(\rho+\theta)}\right)
\end{aligned}
$$

Under this model, the optimal benefit function $V\left(H_{A}, H_{B}\right)$ of cooperative emission reduction between Chinese 
enterprises and local enterprises in developing countries along the Belt and Road Initiative is:

$$
\begin{gathered}
V^{C}=\frac{\omega}{\rho+\delta} H_{A}+\frac{\eta}{\rho+\theta} H_{B}+\frac{\left[\gamma_{F}(\rho+\delta)+\omega \alpha_{F}\right]^{2}}{2 \rho k_{F}(\rho+\delta)^{2}}+\frac{\left[\gamma_{L}(\rho+\delta)+\omega \alpha_{L}\right]^{2}}{2 \rho k_{L}(\rho+\delta)^{2}} \\
+\frac{\left(\eta \beta_{F}\right)^{2}}{2 \rho k_{I}(\rho+\theta)^{2}}+\frac{\left(\eta \beta_{R}\right)^{2}}{2 \rho k_{R}(\rho+\theta)^{2}}
\end{gathered}
$$

The proof of this Proposition is given in the Appendix 3.

\section{Model analysis}

Based on the above game equilibrium results of Chinese enterprises and local enterprises in developing countries along the Belt and Road Initiative under Nash non-cooperative game, Stackelberg master-slave game, and cooperative game, the following corollaries apply:

Corollary 1. Subsidies given by Chinese enterprises to local enterprises in developing countries along the Belt and Road Initiative are helpful to improve the efforts of local enterprises in carbon emission reduction and low-carbon promotion. And the increase rate is equal to the subsidies of Chinese enterprises. Relevant proof are as follows:

$$
\begin{aligned}
E_{L}^{S}-E_{L}^{N} & =\frac{(2-3 \mu)\left[\gamma_{L}(\rho+\delta)+\alpha_{L} \omega\right]}{2 k_{L}(\rho+\delta)} \\
& =\frac{(2-3 \mu)\left[\gamma_{L}(\rho+\delta)+\alpha_{L} \omega\right]}{2 k_{L}(\rho+\delta)} * \frac{2-3 \mu}{2-\mu}=E_{L}^{S * \lambda_{L}} \\
& >0 \\
E_{R}^{S}-E_{R}^{N} & =\frac{(2-3 \mu) \eta \beta_{R}}{2 k_{R}(\rho+\theta)}=\frac{(2-\mu) \eta \beta_{R}}{2 k_{R}(\rho+\theta)} * \frac{2-3 \mu}{2-\mu}=E_{R}^{S * \lambda_{R}} \\
& >0
\end{aligned}
$$

According to Corollary 1, the efforts of local enterprises in carbon emission reduction and low-carbon promotion are affected by the subsidies given by Chinese enterprises. To be specific, higher subsidies lead to more efforts of local enterprises in carbon emission reduction and low-carbon promotion. Considering the great influence of local enterprises in the host country market, if Chinese enterprises want to jointly carry out carbon emission reduction work with local enterprises in developing countries along the Belt and Road Initiative, they must improve the enthusiasm of local enterprises through various subsidies.

Corollary 2 Under Stackelberg master-slave mode, the emission reduction efforts and low-carbon infrastructure investment efforts of Chinese enterprises are equal to Nash noncooperative mode. When Chinese enterprises cooperate with local enterprises in developing countries along the Belt and
Road Initiative, their efforts in carbon reduction, investment, and promotion of final products reach the maximum. Relevant proofs are as follows:

$$
\begin{aligned}
E_{F}^{S} & =E_{F}^{N}, E_{I}^{S}=E_{I}^{N}, E_{F}^{C}-E_{F}^{S}=\frac{\mu\left[\gamma_{F}(\rho+\delta)+\alpha_{F} \omega\right]}{k_{F}(\rho+\delta)} \\
& >0, E_{I}^{C}-E_{I}^{S}=\frac{\mu \eta \beta_{F}}{k_{I}(\rho+\theta)}>0
\end{aligned}
$$

$$
\begin{aligned}
E_{L}^{C}-E_{L}^{S} & =\frac{\mu\left[\gamma_{L}(\rho+\delta)+\alpha_{L} \omega\right]}{2 k_{L}(\rho+\delta)}>0, E_{R}^{C}-E_{R}^{S} \\
& =\frac{\mu \eta \beta_{R}}{2 k_{R}(\rho+\theta)}>0
\end{aligned}
$$

According to Corollary 2, under the Stackelberg master-slave mode dominated by Chinese enterprises, Chinese enterprises will not increase their carbon emission reduction efforts and low-carbon infrastructure investment efforts but only encourage local enterprises to carry out carbon emission reduction locally through subsidies. When the two sides carry out carbon emission reduction work under the cooperative mode, their efforts in carbon emission reduction, low-carbon infrastructure construction, and promotion reach maximum, which also accords with Corollary 1.

Corollary 3 There is a negative correlation between the subsidies of Chinese enterprises to local enterprises in developing countries along the Belt and Road Initiative and the income distribution coefficient, that is, the more income distribution the local enterprises in developing countries along the Belt and Road Initiative get, the less subsidies the Chinese enterprises receive. Relevant proofs are as follows:

$$
\begin{aligned}
& \lambda_{L}=\frac{E_{L}^{S}-E_{L}^{N}}{E_{L}^{S}}=\frac{2-3 \mu}{2-\mu}=\lambda_{R}=\frac{E_{R}^{S}-E_{R}^{N}}{E_{R}^{S}}=\frac{2-3 \mu}{2-\mu} \\
& \lambda_{L}{ }^{\prime}=\lambda_{R}{ }^{\prime}=\frac{2-3 \mu}{(2-\mu)^{2}}-\frac{3}{2-\mu}=-\frac{4}{(2-\mu)^{2}}<0 \quad\left(0<\mu<\frac{2}{3}\right)
\end{aligned}
$$

According to Corollary 3, the reason for this negative effect is that although the investment Chinese enterprises in developing countries along the Belt and Road Initiative have a certain nature of assistance, in the final analysis, the aim of enterprises is still making profits. When Chinese enterprises first entered the market of developing countries along the Belt and Road Initiative, because the total amount of income was not large, Chinese enterprises hoped to use more subsidies to drive local companies to open the host country market. When the markets of countries along the Belt and Road Initiative are opened and the total amount of final income becomes larger (i.e., the more income the local enterprises in the countries 
along the Belt and Road Initiative get), Chinese enterprises will appropriately reduce subsidies to seek more income.

Corollary 4 The subsidy coefficient of Chinese enterprises to local enterprises in developing countries along the Belt and Road Initiative can improve the carbon emission reduction of final products and the influence of final products in the host country (i.e., $\boldsymbol{H}_{\boldsymbol{A}}^{\boldsymbol{C}}>\boldsymbol{H}_{\boldsymbol{A}}^{\boldsymbol{S}}>\boldsymbol{H}_{\boldsymbol{A}}^{\boldsymbol{N}}, \boldsymbol{H}_{\boldsymbol{B}}^{\boldsymbol{C}}>\boldsymbol{H}_{\boldsymbol{B}}^{\boldsymbol{S}}>\boldsymbol{H}_{\boldsymbol{B}}^{N}$ ). Relevant proofs are as follows:

According to Corollary 1 and Corollary 2,

$\alpha_{F} E_{F}^{C}+\alpha_{L} E_{L}^{C}>\alpha_{F} E_{F}^{S}+\alpha_{L} E_{L}^{S}>\alpha_{F} E_{F}^{N}+\alpha_{L} E_{L}^{N}$. That is , $Q^{C}>Q^{S}>Q^{N}$. And because

$\frac{d H_{A}}{d Q}=\frac{1}{\delta}\left(1-e^{-\delta^{* t}}\right)>\mathbf{0}(\delta>0)$

It can be seen that $H_{A}$ is the increasing function of $Q$. Therefore, $H_{A}^{C}>H_{A}^{S}>H_{A}^{N}$ is obtained.

Similarly, according to Corollary 1 and Corollary $2, \beta_{F} E_{I}^{C}+\beta_{R} E_{R}^{C}>\beta_{F} E_{I}^{S}+\beta_{R} E_{R}^{S}>\beta_{F} E_{I}^{N}+\beta_{R} E_{R}^{N}$. That is, $Z^{C}>Z^{S}>Z^{N}$. And because

$\frac{d H_{B}}{d Z}=\frac{1}{\theta}\left(1-e^{-\theta^{* t}}\right)>\mathbf{0}(\theta>\mathbf{0})$

It can be seen that $H_{B}$ is the increasing function of $Z$. Therefore, $H_{B}^{C}>H_{B}^{S}>H_{B}^{N}$ is obtained.

According to Corollary 4, it can be found that the subsidies given by Chinese enterprises to local enterprises in developing countries along the Belt and Road Initiative are helpful to improve the carbon emission reduction of the final products and their influence in the host country. The carbon emission reduction of the final product and its influence in the host country will ultimately affect the overall carbon emission reduction benefits of both parties, which also confirms the conclusion of Corollary 2. In addition, the carbon emission reduction and influence of the final product is the greatest under the cooperation, which also shows that the cooperation is the best mode, which is also the direction of future efforts

Corollary 5 In Stackelberg game, the optimal benefits of Chinese enterprises and local enterprises along the Belt and Road Initiative and the overall benefits of cooperative carbon emission reduction are higher than the corresponding values in Nash non-cooperative game. Relevant proofs are as follows:

$$
\begin{aligned}
V_{L}^{S}-V_{L}^{\mathrm{N}}= & \frac{\mu \omega}{\rho+\delta}\left(H_{A}^{S}-H_{A}^{N}\right)+\frac{\mu \eta}{\rho+\theta}\left(H_{B}^{S}-H_{B}^{N}\right) \\
& +\frac{\mu(2-3 \mu)\left[\gamma_{L}(\rho+\delta)+\alpha_{L} \omega\right]^{2}}{4 \rho k_{L}(\rho+\delta)^{2}}+\frac{\mu(2-3 \mu)\left(\eta \beta_{R}\right)^{2}}{4 \rho k_{R}(\rho+\theta)^{2}}>0
\end{aligned}
$$

$$
\begin{aligned}
& V_{F}^{S}-V_{F}^{N}=\frac{(1-\mu) \omega}{\rho+\delta}\left(H_{A}^{S}-H_{A}^{N}\right)+\frac{(1-\mu) \eta}{\rho+\theta}\left(H_{B}^{S}-H_{B}^{N}\right) \\
& +\frac{(2-3 \mu)^{2}\left[\gamma_{L}(\rho+\delta)+\alpha_{L} \omega\right]^{2}}{8 \rho k_{L}(\rho+\delta)^{2}}+\frac{(2-3 \mu)^{2}\left(\eta \beta_{R}\right)^{2}}{8 \rho k_{R}(\rho+\theta)^{2}}>0 \\
& V^{S}-V^{N}=\frac{\omega}{\rho+\delta}\left(H_{A}^{S}-H_{A}^{N}\right)+\frac{\eta}{\rho+\theta}\left(H_{B}^{S}-H_{B}^{N}\right) \\
& +\frac{(2-3 \mu)(2-\mu)\left[\gamma_{L}(\rho+\delta)+\alpha_{L} \omega\right]^{2}}{8 \rho k_{L}(\rho+\delta)^{2}}+\frac{(2-3 \mu)(2-\mu)\left(\eta \beta_{R}\right)^{2}}{8 \rho k_{R}(\rho+\theta)^{2}}>0
\end{aligned}
$$

According to Corollary 5, the benefits of Chinese enterprises, local enterprises in developing countries, and the overall benefits of cooperative carbon emission reduction are higher than Nash non-cooperative game, which indicates that the Belt and Road Initiative cooperative carbon emission reduction model led by Chinese enterprises is Pareto effective at present.

Corollary 6 In the cooperative game, the overall benefits of carbon emission reduction between Chinese enterprises and local enterprises in developing countries along the Belt and Road Initiative reach the highest. Relevant proofs are as follows:

$$
\begin{gathered}
V^{C}-V^{S}=\frac{\omega}{\rho+\delta}\left(H_{A}-H_{A}^{S}\right)+\frac{\eta}{\rho+\theta}\left(H_{B}-H_{B}^{S}\right)+\frac{\mu^{2}\left[\gamma_{L}(\rho+\delta)+\alpha_{L} \omega\right]^{2}}{8 \rho k_{L}(\rho+\delta)^{2}} \\
+\frac{\left(\mu \eta \beta_{R}\right)^{2}}{8 \rho k_{R}(\rho+\theta)^{2}}+\frac{\mu^{2}\left[\gamma_{L}(\rho+\delta)+\alpha_{L} \omega\right]^{2}}{2 \rho k_{F}(\rho+\delta)^{2}}+\frac{\left(\mu \eta \beta_{R}\right)^{2}}{2 \rho k_{R}(\rho+\theta)^{2}}>0
\end{gathered}
$$

According to Corollary 6, the overall benefit of carbon emission reduction under the cooperative mode is higher than that of Stackelberg master-slave game, which indicates that although the cooperative mode of carbon emission reduction in the Belt and Road Initiative led by Chinese enterprises can achieve Pareto optimization (i.e., it is better than Nash noncooperative mode). But the reciprocal cooperation between China and developing countries along the Belt and Road Initiative is the best mode. And this cooperation mode will be realized when the strengths of local enterprises in developing countries along the Belt and Road Initiative are further enhanced with the help of Chinese enterprises.

\section{Analysis of examples}

To verify the credibility of the above corollaries and the sensitivity of various important parameters, this section performs numerical analyses from four aspects: carbon emission reduction of the final product, influence of final products in host country, the respective benefits of both parties, and overall benefit of carbon emission reduction in the Belt and Road Initiative. Variable assignments in this section are as follows: $k_{L}=1.5, k_{R}=1, k_{F}=2, k_{I}=4, \alpha_{L}=0.3, \alpha_{F}=0.5, \beta_{R}=$ $0.3, \beta_{F}=0.4, \gamma_{L}=2, \gamma_{F}=3, \omega=4, \eta=2, \delta=0.3, \theta=0.2$, $\mu=0.4, \rho=0.1, H_{A}(0)=H_{A}=0, H_{B}(0)=H_{B}=0$. 
Substituting the above assignment into proposition 1, proposition 2, and proposition 3 can solve $E_{L}^{N}=0.67$, $E_{R}^{N}=0.8, \quad E_{F}^{N}=2.1, \quad E_{I}^{N}=0.4, \quad E_{L}^{S}=1.33, \quad E_{R}^{S}=1.6$, $E_{F}^{S}=2.1, E_{I}^{S}=0.4, \lambda_{L}^{S}=\lambda_{R}^{S}=0.5, E_{L}^{C}=1.67, E_{R}^{C}=2$, $E_{F}^{C}=3.5$, and $E_{I}^{C}=0.67$, respectively

From the above assignment, it can be obtained that in Nash non-cooperative game $Q^{N}=1.25$ and $Z^{N}=0.4$, the carbon emission reduction of the final product is $H_{A}^{N}=4.17-4.17 e^{-0.3 t}$, the local influence of the final product in the host country is $H_{B}^{N}=2-2 e^{-0.2 t}$, the optimal return of local enterprises in developing countries along the Belt and Road Initiative is $V_{L}^{N}=4 H_{A}^{N}+2.67 H_{B}^{N}+76.4$, the optimal return of Chinese enterprises is $V_{F}^{N}=6 H_{A}^{N}+4 H_{B}^{N}+94.15$, and the overalloptimal return is $V^{N}=10 H_{A}^{N}+6.67 H_{B}^{N}+170.55$.

In Stackelberg master-slave game $Q^{S}=1.45$ and $Z^{S}=$ 0.64 , the carbon emission reduction of the final product is $H_{A}^{S}=4.83-4.83 e^{-0.3 t}$, the local influence of the final product in the host country is $H_{B}^{S}=3.2-3.2 e^{-0.2 t}$, the optimal return of local enterprises in developing countries along the Belt and Road Initiative is $V_{L}^{S}=4 H_{A}^{S}+2.67 H_{B}^{S}+92.93$, the optimal return of Chinese enterprises is $V_{F}^{S}=6 H_{A}^{S}+4 H_{B}^{S}+111.04$, a n t h e overall optimal return is $V^{S}=10 H_{A}^{S}+6.67 H_{B}^{S}+203.97$.

In cooperative game $Q^{C}=2.25$ and $Z^{C}=0.87$, the carbon emission reduction of the final product is $H_{A}^{C}=7.5-7.5 e^{-0.3 t}$, the local influence of the final product in the host country is $H_{B}^{C}=4.35-4.35 e^{-0.2 t}$, and the overall optimal return is $V^{C}=$ $10 H_{A}+6.67 H_{B}+228.06$.

\section{Analysis of carbon emission reduction of the final product}

Figure 2 reflects the influence of time on carbon emission reduction of the final product under different game models. According to Fig. 2, the carbon emission reduction of the final product increases with time and finally tends to be flat. Moreover, it can be found from Fig. 2 that the carbon emission reduction of the final product in Nash non-cooperative game mode is the lowest, which is higher in Stackelberg masterslave mode. The carbon emission reduction under the cooperative game is the highest and far exceeds the previous two models.

This suggests that Chinese enterprises can effectively improve the carbon emission reduction of final products through subsidies (i.e.,, Stackelberg master-slave game mode). Therefore, Chinese enterprises should play an important role in carbon emission reduction cooperation under the Belt and Road Initiative, which indicates that Chinese enterprises should give enough subsidies to local enterprises in developing countries along the Belt and Road Initiative to encourage

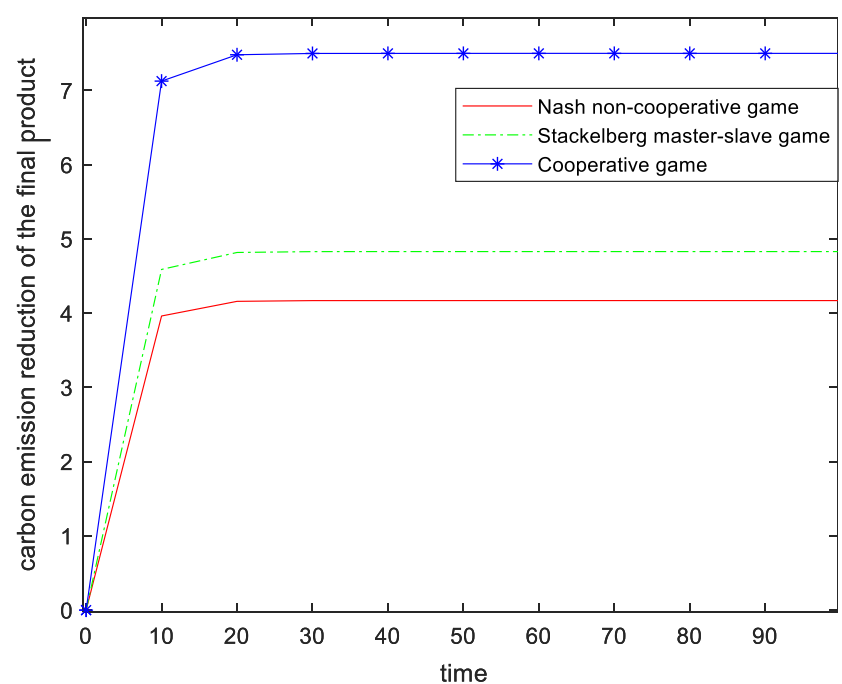

Fig. 2 Influence of time on carbon emission reduction of the final product under different game models

them to carry out carbon emission reduction work. In addition, collaborative cooperation is the best model for carbon emission reduction of Chinese enterprises and local enterprises in developing countries along the Belt and Road Initiative. When the capital and technological strength of local enterprises in the countries along the Belt and Road Initiative reach a certain level, Chinese enterprises will cancel subsidies, and the two sides will cooperate to achieve the maximum benefit.

\section{Analysis of influence of final products in host country}

Figure 3 reflects the influence of time on influence of final products in host country under different game models. According to Fig. 3, influence of final products in host country increases with time and finally tends to be flat. Similar with 5.1 , it can be found from Fig.2 that the influence of final products in host country in Nash non-cooperative game mode

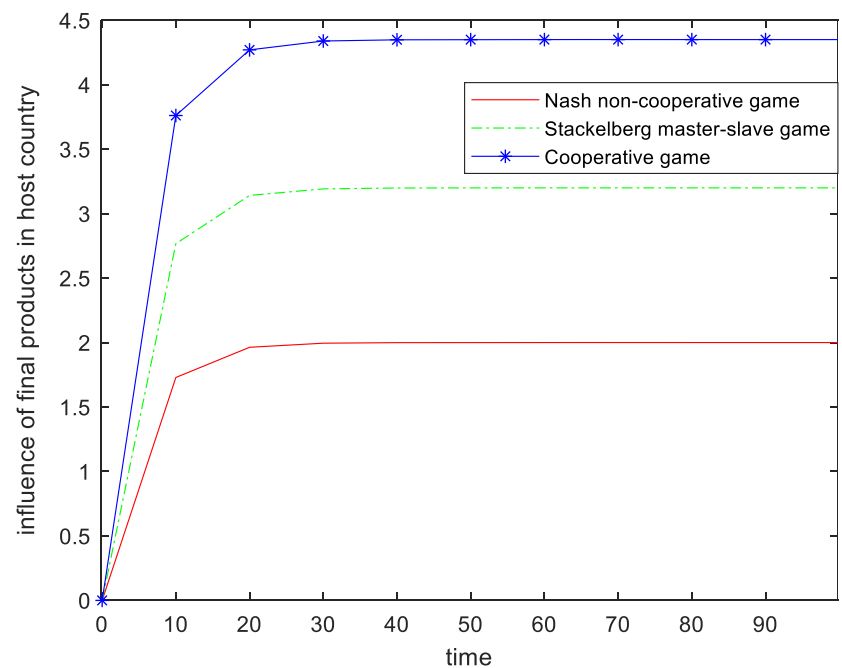

Fig. 3 Influence of time on influence of final products in host country under different game models 
is the lowest, which is higher in Stackelberg master-slave mode. The influence of final products in host country under the cooperative game is the highest and far exceeds the previous two models.

According to the previous assumptions, the influence of final product in host country is determined by the publicity and promotion efforts of local enterprises and the emission reduction investment efforts of Chinese enterprises.

\section{Analysis of the respective benefits of both parties}

Figures 4 and 5 reflect the influence of time on the benefits of local enterprises and Chinese enterprises under different game models. According to Fig. 4 and Fig. 5, the benefits of local enterprises and Chinese enterprises increase with time and finally tend to be flat. Moreover, under Stackelberg masterslave mode, the profits of local enterprises and Chinese enterprises are much higher than those of Nash non-cooperative mode. This shows that the carbon emission reduction cooperation along the Belt and Road Initiative led by Chinese enterprises can achieve a win-win situation for both parties. Therefore, when cooperating with local enterprises in developing countries along the Belt and Road Initiative in carbon emission reduction cooperation, Chinese enterprises should play a leading role to achieve win-win results for both sides.

\section{Analysis of overall benefit of carbon emission reduction in the Belt and Road Initiative}

Figure 6 reflects the influence of time on overall carbon emission reduction benefits. According to Fig. 6, the overall carbon emission reduction benefits increase with time and finally tend to be flat. Moreover, the overall benefits of Cooperative model are much higher than those of Nash non-cooperative mode and Stackelberg master-slave mode. This shows that

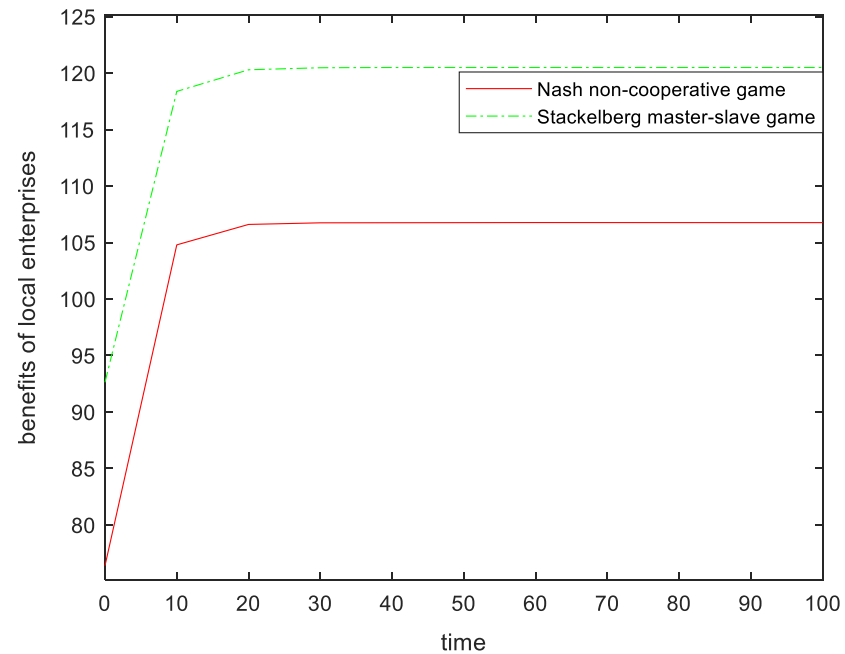

Fig. 4 Influence of time on the benefits of local enterprises under different game models

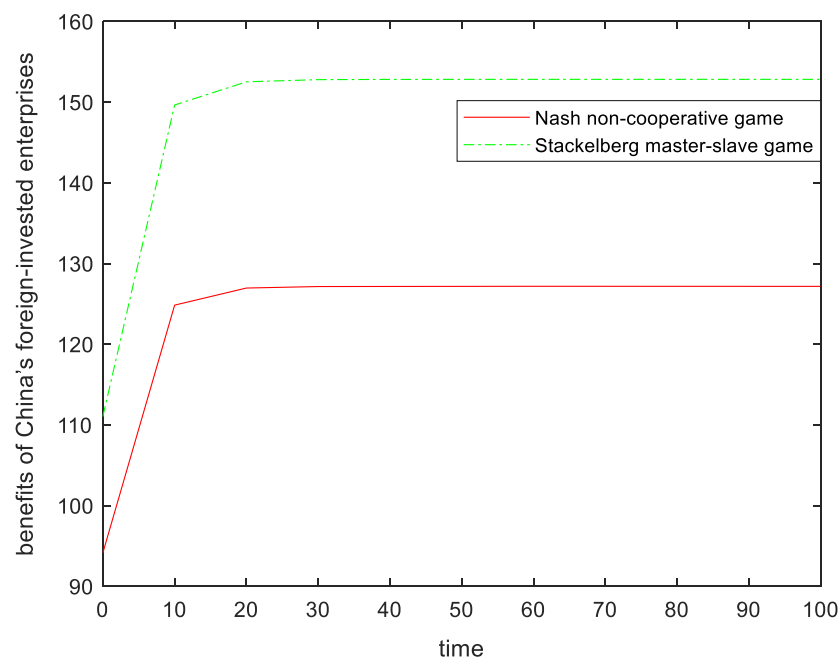

Fig. 5 Influence of time on the benefits of Chinese enterprises under different game models

although the cooperation mode of carbon emission reduction led by Chinese enterprises can achieve a win-win situation, only the cooperation under the cooperative mode can achieve the optimal pareto equilibrium, which is also the ultimate direction of carbon emission reduction cooperation under the Belt and Road Initiative.

\section{Analysis of carbon emission reduction of final products and the impact of final products in host countries}

The effects of $w$ and $\eta$ on the benefit of overall carbon emission reduction are shown in Fig. 7, which can reflect the changes of $w$ (carbon emission reduction of final products) and $\eta$ (the impact of final products in host countries) on the overall benefits of collaborative carbon emission reduction cooperation in the carbon emission reduction between China and developing countries along the Belt and Road Initiative.

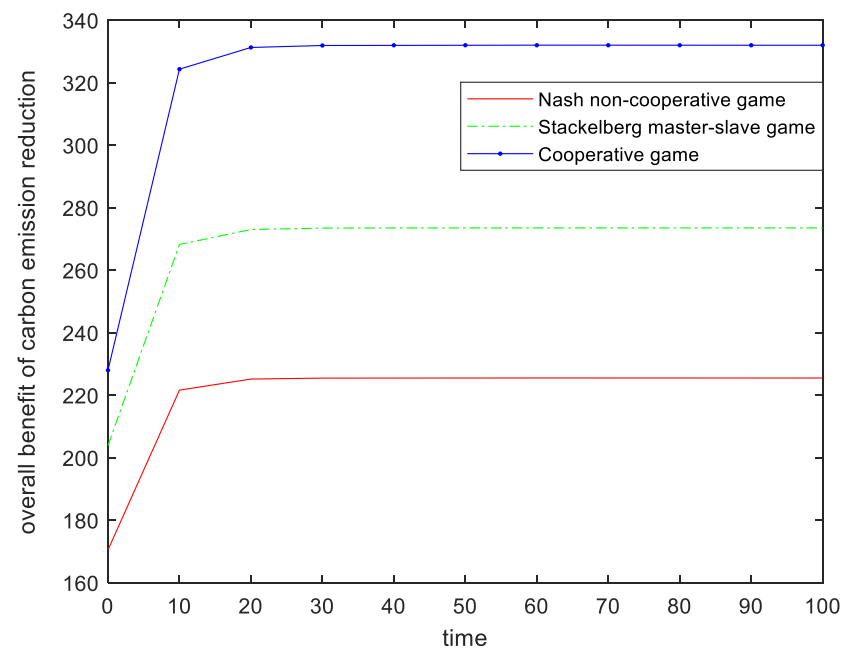

Fig. 6 Influence of time on overall carbon emission reduction benefits 


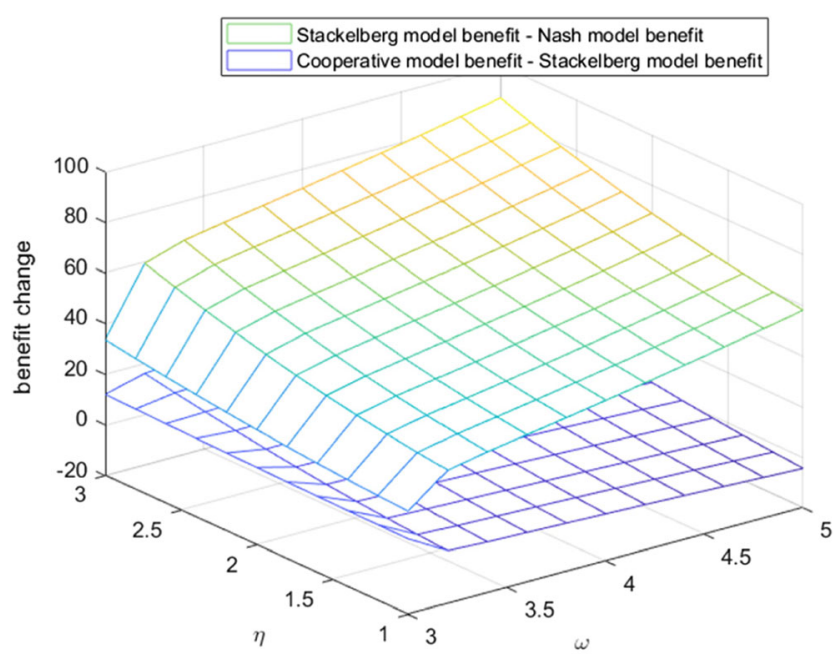

Fig. $7 \Delta \Pi$ with varying $w$ and $\eta$

According to Fig. 7, with the growth of $w$ and $\eta$, the gap between Nash non-cooperative model and Stackelberg master-slave model and the gap between Stackelberg masterslave model and Cooperative game model are growing together. At the same time, it can be found that the gap between Nash non-cooperative model and Stackelberg master-slave model grows faster than Stackelberg master-slave model and cooperative game model. This shows that improving the carbon emission reduction of the final product and its influence in the host country can quickly improve the overall benefits of carbon emission reduction cooperation between China and developing countries along the Belt and Road Initiative, and the benefit of China's dominant cooperation mode is the fastest. In addition, it can be found from Fig. 7 that the unilateral growth of $w$ and $\eta$ is not enough to greatly improve the overall benefits of cooperative carbon emission reduction and the benefits from growing $\eta$ alone are greater than those from growing $w$ alone. This shows that carbon emission reduction of final products and the impact of final products in host countries should be enhanced together. And it is more important to improve the influence of the final product in the host country, which is triggered by the efforts of local enterprises in developing countries along the Belt and Road Initiative.

\section{Analysis of the efforts made by Chinese enterprises and local enterprises in developing countries along the Belt and Road Initiative in carbon emission reduction}

The effects of $\gamma_{F}$ and $\gamma_{L}$ on the benefit of overall carbon emission reduction are shown in Fig. 8, which can reflect the changes of $\gamma_{F}$ (the efforts made by Chinese enterprises) and $\gamma_{L}$ (the efforts made by local enterprises in developing countries along the Belt and Road Initiative) on the overall benefits of collaborative carbon emission reduction

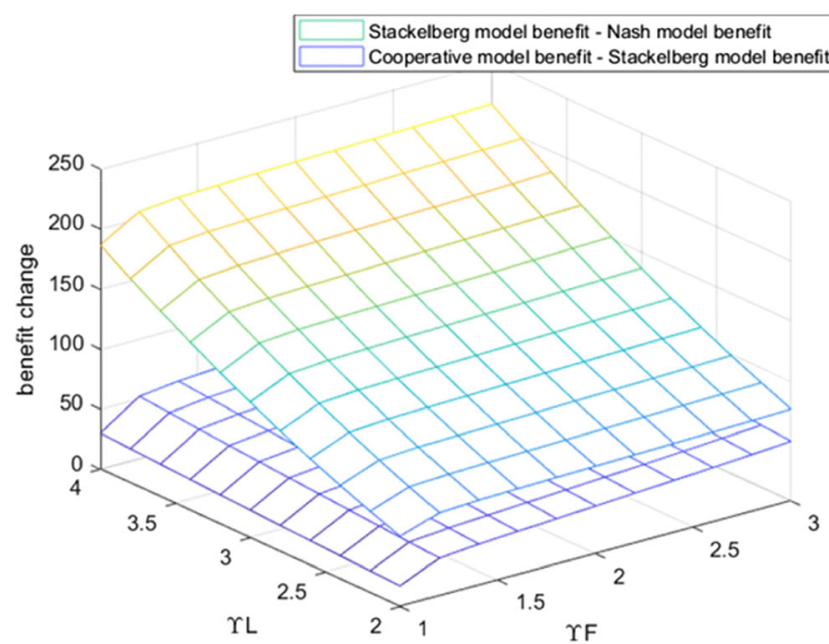

Fig. 8 Influence $\Delta \Pi$ with varying $\gamma_{F}$ and $\gamma_{L}$

cooperation in the carbon emission reduction between China and developing countries along the Belt and Road Initiative.

According to Fig. 8, with the growth of $\gamma_{F}$ and $\gamma_{L}$, the gap between Nash non-cooperative model and Stackelberg master-slave model and the gap between Stackelberg masterslave model and Cooperative game model are growing together. And in connection with Fig. 7, it can be found that the benefit change of Fig. 8 is greater than Fig. 7. This shows that it is more effective to improve the efforts of enterprises in carbon emission reduction cooperation than to improve the carbon emission reduction of final products and their influence in the host country. Moreover, it can be found from Fig. 8 that the single growth of $\gamma_{F}$ can hardly increase the overall benefit, while the

single growth of $\gamma_{L}$ can greatly increase the overall benefit. This shows that the efforts of local enterprises in developing countries along the Belt and Road Initiative are more important in cooperative carbon emission reduction. Therefore, Chinese enterprises should fully mobilize the enthusiasm of local enterprises in developing countries along the Belt and Road Initiative to promote the success of cooperative carbon emission reduction.

\section{Conclusions and policy implications}

\section{Conclusions}

Under the background of the increasing awareness of environmental protection around the world and China's carbon peaking strategy put forward, this paper aims to help Chinese enterprises and local enterprises in developing countries along the Belt and Road Initiative find an optimal cooperation mode for carbon emission reduction. Based on previous studies, by building a differential game model under Nash non-cooperative mode, Stackelberg master-slave mode, and 
cooperative mode and horizontally comparing the results, this paper explores the optimal cooperation mode of carbon emission reduction under the Belt and Road Initiative and the related influencing factors that affect the cooperation benefit, while the previous literature neglects the theoretical study of carbon emission reduction cooperation under the Belt and Road Initiative. We conclude this paper through three perspectives.

Firstly, we concluded that the carbon emission reduction mode led by Chinese enterprises can effectively improve the overall benefits of cooperative carbon emission reduction under the Belt and Road Initiative, but the cooperative mode is the best. Through the calculation of indicators, previous studies have discussed the influence of China in the Belt and Road Initiative's carbon emission reduction cooperation, but no clear conclusions have been drawn, and no theoretical analysis has been made on this issue. Therefore, this conclusion can provide a reference for the future cooperation model of carbon emission reduction between countries under the Belt and Road Initiative. Furthermore, in the context of this paper, we calculated and compared the benefits of Nash non-cooperative mode, Stackelberg master-slave mode, and cooperative mode through the differential game model and found the optimal cooperative mode. We found that the cooperation model led by Chinese enterprises can effectively increase the overall carbon emission reduction benefits, but the ultimate optimal cooperation model is mutual benefit and cooperation between both parties. And this cooperation mode can be realized when the local enterprises in developing countries along the Belt and Road Initiative increase their capital and technology strength which rely on the support of Chinese enterprises.

Secondly, in terms of the carbon reduction of the final product and its influence in the host country, the carbon reduction of the final product and its influence in the host country should be increased simultaneously. Moreover, the influence of the final product in the host country has a greater impact on the overall benefits of carbon emission reduction cooperation than carbon emission reduction of the final product. This result indicates that we must not only focus on the carbon reduction effect of the final product but also enhance its influence in the host country. Otherwise, no matter how good the product is, it will not work. And this depends on the efforts of local enterprises in developing countries along the Belt and Road Initiative. Therefore, Chinese enterprises must provide sufficient subsidies to stimulate the enthusiasm of local enterprises for publicity and promotion. As we also notice that, this finding extends the arguments of $\mathrm{Wu}$ et al. (2019), who only pointed out that China should provide financial subsidies to facilitate the successful completion of the carbon emission reduction work but did not indicate in what direction the subsidies should be provided.

Thirdly, local enterprises in developing countries along the Belt and Road Initiative should receive more attention in carbon emission reduction cooperation. We found that the emission reduction efforts of local enterprises in developing countries along the Belt and Road Initiative have a greater impact on the overall carbon emission reduction benefits than Chinese enterprises. This result shows that although China should play an important role in the Belt and Road Initiative's carbon emission reduction cooperation at present, the ultimate benefit of carbon emission reduction cooperation depends more on developing countries along the Belt and Road Initiative. Therefore, Chinese enterprises should fully mobilize the enthusiasm of local enterprises in developing countries along the Belt and Road Initiative for carbon emission reduction. Although the studies of Qian et al. (2019) and Liu et al. (2021a) point out that China should play the role of helper in the Belt and Road Initiative affairs, these studies over-emphasize the role of host country and neglect the role of China. The enthusiasm of Chinese enterprises to mobilize the carbon emission reduction of local enterprises in developing countries along the Belt and Road Initiative mentioned in this paper does not only mean that Chinese enterprises act as a helper but that Chinese enterprises play a leading role and attract and encourage local enterprises to participate in carbon emission reduction through a series of ways such as investment and subsidies. This also echoes the conclusion above that the optimal cooperation mode can be realized through Chinese enterprises supporting the development of local enterprises in countries along the Belt and Road Initiative.

Based on the above analysis, we can conclude that Chinese enterprises should play an important role in carbon emission reduction cooperation under the Belt and Road Initiative and fully mobilize the enthusiasm of local enterprises in developing countries to participate in carbon emission reduction cooperation by various means such as investment and subsidies. After the capital and technology strength of local enterprises in developing countries along the Belt and Road Initiative are improved, the two sides will cooperate with each other to achieve the best benefits. And this is the most important significances of this article.

\section{Policy implications}

The management significance of this paper is presented from two aspects: Firstly, the implications for managers of Chinese enterprises and local enterprises in developing countries along the Belt and Road Initiative from the enterprise level and secondly, the implications for policy makers of China and developing countries along the Belt and Road Initiative from the national level.

It is crucial for Chinese enterprises to play the role of cooperative leaders at the present stage and promote the development of local enterprises by investing in developing countries along the Belt and Road Initiative. Firstly, Chinese 
enterprises can attract local enterprises from developing countries along the Belt and Road Initiative to participate in carbon emission reduction cooperation by investing in developing countries and establishing strategic alliances with local enterprises. Secondly, in the carbon emission reduction cooperation with local enterprises, it is necessary to give local enterprises a certain amount of carbon emission reduction cooperation subsidies, which can well stimulate the enthusiasm of local enterprises to participate in carbon emission reduction cooperation. Finally, it is important to increase the visibility of the final product in developing countries along the Belt and Road Initiative. Chinese enterprises can cooperate with local enterprises to design final products that cater to local consumer needs based on field research of local consumer markets. In addition, Chinese enterprises can also carry out product promotion activities together with local enterprises to establish a good market image for the final products of carbon emission reduction cooperation and improve the local visibility of the final products in developing countries along the Belt and Road Initiative. For local enterprises in developing countries along the Belt and Road Initiative, it is urgent to solve the problem of how to rapidly improve their financial and technological strength with the help of Chinese enterprises. And these problems can be carried out through deeper exchanges and cooperation with Chinese enterprises.

The carbon emission reduction work of Chinese enterprises under the Belt and Road Initiative needs strong effort from Chinese government. Therefore, for Chinese government, it is necessary to reduce the cost and tax of Chinese enterprises which participate in carbon emission reduction under the Belt and Road Initiative. For example, Chinese government can increase the total tax credit of profits which are from carbon emission reduction cooperation in order to reduce the tax burden of Chinese enterprises. Moreover, it is also advisable to mobilize Chinese enterprises to participate in the carbon emission reduction work under the Belt and Road Initiative through subsidies. In addition, the results also show that the efforts of local enterprises in developing countries along the Belt and Road Initiative are more important than those of Chinese enterprises in reducing carbon emissions. Therefore, besides the subsidies given by Chinese enterprises, other methods are needed to improve the enthusiasm of local enterprises to participate in carbon emission reduction cooperation under the Belt and Road Initiative. Therefore, for government of developing countries along the Belt and Road Initiative, the most important step is to encourage local enterprises to participate in carbon emission reduction cooperation in various ways. Such as tax cuts, subsidies, government contributions, and so on. In addition, it is essential to attract investment from Chinese enterprises. Therefore, the developing countries' government can attract Chinese enterprises to invest by increasing preferential policies and improving related supporting services.

\section{Appendix 1. Proof of Proposition 1}

Under Nash non-cooperative game, both Chinese enterprises and local enterprises in developing countries along the Belt and Road Initiative use the maximization of their own interests as decision criteria. The Hamilton function is used to solve the optimal control problem. According to the objective functions of Chinese enterprises $F$ and local enterprises in developing countries along the Belt and Road Initiative $L$, the Hamilton functions of both Chinese enterprises and local enterprises are:

$\Pi_{L}^{*}=e^{-\rho t} \max _{E_{L} E_{R}} \int_{0}^{\infty} e^{-\rho(s-t)}\left[\mu\left(\gamma_{F} E_{F}+\gamma_{M} E_{M}+\omega H_{A}+\eta H_{B}\right)-\frac{1}{2} k_{L} E_{L}^{2}-\frac{1}{2} k_{R} E_{R}^{2}\right] d t$

$\Pi_{F}^{*}=e^{-\rho t} \max _{E_{F} ; E_{I}} \int_{0}^{\infty} e^{-\rho(s-t)}\left[(1-\mu)\left(\gamma_{F} E_{F}+\gamma_{M} E_{M}+\omega H_{A}+\eta H_{B}\right)-\frac{1}{2} k_{F} E_{F}^{2}-\frac{1}{2} k_{I} E_{I}^{2}\right] d t$

Then the profit optimization problem of Chinese enterprises and local enterprises in developing countries along the Belt and Road Initiative at time $t$ is transformed into:

$\Pi_{L}^{*}=e^{-\rho t} V_{L}\left(H_{A}, H_{B}\right)$

$\Pi_{F}^{*}=e^{-\rho t} V_{F}\left(H_{A}, H_{B}\right)$

Equations (A44) and (A45) satisfy HJB equation for all a and $\mathrm{b}$ and can be obtained as follows:

$$
\begin{gathered}
\rho V_{L}\left(H_{A}, H_{B}\right)=\max _{E_{L} E_{R}}\left\{\mu\left(\gamma_{F} E_{F}+\gamma_{L} E_{L}+\omega H_{A}+\eta H_{B}\right)\right. \\
-\frac{1}{2} k_{L} E_{L}^{2}-\frac{1}{2} k_{R} E_{R}^{2}+\frac{\partial V_{L}}{\partial H_{A}}\left(\alpha_{F} E_{F}+\alpha_{L} E_{L}-\delta H_{A}\right) \\
\left.+\frac{\partial V_{L}}{\partial H_{B}}\left(\beta_{F} E_{I}+\beta_{R} E_{R}-\theta H_{B}\right)\right\} \\
\rho V_{F}\left(H_{A}, H_{B}\right)=\max _{E_{F} E_{I}}\left\{(1-\mu)\left(\gamma_{F} E_{F}+\gamma_{L} E_{L}+\omega H_{A}+\eta H_{B}\right)\right. \\
-\frac{1}{2} k_{F} E_{F}^{2}-\frac{1}{2} k_{I} E_{I}^{2}+\frac{\partial V_{F}}{\partial H_{A}}\left(\alpha_{F} E_{F}+\alpha_{L} E_{L}-\delta H_{A}\right) \\
\left.+\frac{\partial V_{F}}{\partial H_{B}}\left(\beta_{F} E_{I}+\beta_{R} E_{R}-\theta H_{B}\right)\right\}
\end{gathered}
$$

Equations (A46) and (A47) are concave functions about $\left(E_{L}, E_{R}\right)$ and $\left(E_{F}, E_{I}\right)$, according to the first-order conditions; the right end of formula (A46) finds the first-order partial derivative for $\left(E_{L}, E_{R}\right)$, respectively, and the right end of formula (A47) finds the first-order partial derivative for $\left(E_{F}, E_{I}\right)$, respectively, and makes them all equal to 0 , and the optimal strategies of the two parties can be obtained as follows:

$\left(E_{L}, E_{R}\right)=\left(\frac{\mu \gamma_{L}+\frac{\partial V_{L}}{\partial H_{A}} \alpha_{L}}{k_{L}}, \frac{\frac{\partial V_{L}}{\partial H_{B}} \beta_{R}}{k_{R}}\right)$ 


$$
\left(E_{F}, E_{I}\right)=\left(\frac{(1-\mu) \gamma_{F}+\frac{\partial V_{F}}{\partial H_{A}} \alpha_{F}}{k_{F}}, \frac{\frac{\partial V_{F}}{\partial H_{B}} \beta_{F}}{k_{I}}\right)
$$

Substituting Formula (A48) and Formula (A49) into Formula (A46) and Formula (A47), respectively, after simplification, we can get:

$$
\begin{gathered}
\rho V_{L}\left(H_{A}, H_{B}\right)=\left(\mu \omega-\frac{\partial V_{L}}{\partial H_{A}} \delta\right) H_{A}+\left(\mu \eta-\frac{\partial V_{L}}{\partial H_{B}} \theta\right) H_{B} \\
+\frac{\left(\mu \gamma_{L}+\frac{\partial V_{L}}{\partial H_{A}} \alpha_{L}\right)^{2}}{2 k_{L}}+\frac{\left((1-\mu) \gamma_{F}+\frac{\partial V_{F}}{\partial H_{A}} \alpha_{F}\right)\left(\mu \gamma_{F}+\frac{\partial V_{L}}{\partial H_{A}} \alpha_{F}\right)}{k_{F}} \\
+\frac{\left(\beta_{R} \frac{\partial V_{L}}{\partial H_{B}}\right)^{2}}{2 k_{R}}+\frac{\beta_{F}^{2} \frac{\partial V_{F}}{\partial H_{B}} \frac{\partial V_{L}}{\partial H_{B}}}{k_{I}}
\end{gathered}
$$

$$
\begin{gathered}
\rho V_{F}\left(H_{A}, H_{B}\right)=\left((1-\mu) \omega-\frac{\partial V_{F}}{\partial H_{A}} \delta\right) H_{A}+\left((1-\mu) \eta-\frac{\partial V_{F}}{\partial H_{B}} \theta\right) H_{B}+\frac{\left((1-\mu) \gamma_{F}+\frac{\partial V_{F}}{\partial H_{A}} \alpha_{F}\right)^{2}}{2 k_{F}} \\
+\frac{\left((1-\mu) \gamma_{L}+\frac{\partial V_{F}}{\partial H_{A}} \alpha_{L}\right)\left(\mu \gamma_{L}+\frac{\partial V_{L}}{\partial H_{A}} \alpha_{L}\right)}{k_{L}}+\frac{\left(\beta_{F} \frac{\partial V_{F}}{\partial H_{B}}\right)^{2}}{2 k_{I}}+\frac{\beta_{R}^{2} \frac{\partial V_{F}}{\partial H_{B}} \frac{\partial V_{L}}{\partial H_{B}}}{k_{R}}
\end{gathered}
$$

From the forms of Formula (A50) and Formula (A51), it can be inferred that their solutions are binary linear functions about $H_{A}$ and $H_{B}$, respectively, so that:

$$
\begin{aligned}
& V_{L}\left(H_{A}, H_{B}\right)=a_{1} H_{A}+a_{2} H_{B}+b_{1} \\
& V_{F}\left(H_{A}, H_{B}\right)=a_{3} H_{A}+a_{4} H_{B}+b_{2}
\end{aligned}
$$

In which $a_{1} 、 a_{2} 、 a_{3} 、 a_{4} 、 b_{1}$, and $b_{2}$ are constants. Substituting $V_{L}\left(H_{A}, H_{B}\right), V_{F}\left(H_{A}, H_{B}\right)$, and their first-order partial derivatives into Formula (A50) and Formula (A51), we can get:

$$
\begin{gathered}
\rho\left(a_{1} H_{A}+a_{2} H_{B}+b_{2}\right)=\left(\mu \omega-a_{1} \delta\right) H_{A}+\left(\mu \eta-a_{2} \theta\right) H_{B}+\frac{\left(\mu \gamma_{L}+a_{1} \alpha_{L}\right)^{2}}{2 k_{L}} \\
+\frac{\left((1-\mu) \gamma_{F}+a_{3} \alpha_{F}\right)\left(\mu \gamma_{F}+a_{1} \alpha_{F}\right)}{k_{F}}+\frac{a_{2} a_{4} \beta_{F}^{2}}{k_{I}}+\frac{\left(a_{2} \beta_{R}\right)^{2}}{2 k_{R}}
\end{gathered}
$$

$$
\begin{aligned}
\rho\left(a_{3} H_{A}+\right. & \left.a_{4} H_{B}+b_{2}\right)=\left((1-\mu) \omega-a_{3} \delta\right) H_{A}+\left((1-\mu) \eta-a_{4} \theta\right) H_{B} \\
& +\frac{\left((1-\mu) \gamma_{F}+a_{3} \alpha_{F}\right)^{2}}{2 k_{F}}+\frac{\left((1-\mu) \gamma_{L}+a_{3} \alpha_{L}\right)\left(\mu \gamma_{L}+a_{1} \alpha_{L}\right)}{k_{L}} \\
& +\frac{a_{2} a_{4} \beta_{R}^{2}}{k_{R}}+\frac{\left(a_{4} \beta_{F}\right)^{2}}{2 k_{I}}
\end{aligned}
$$

As formulas (A54) and (A55) should satisfy $H_{A} \geq 0$ and $H_{B} \geq 0$, the parameter values of $a_{1}, a_{2}, a_{3}, a_{4}, b_{1}$, and $b_{2}$ can be obtained as follows:

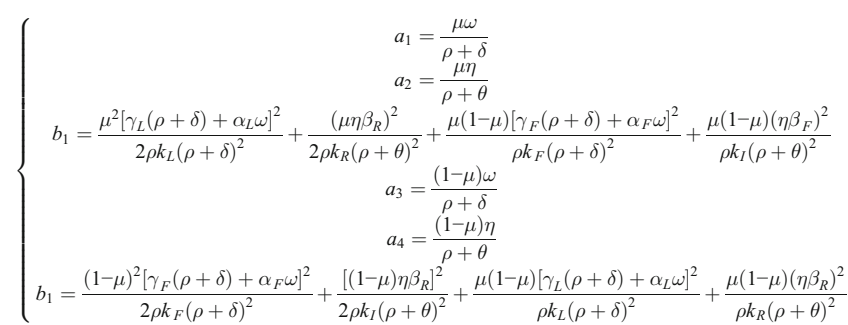

(A56)

By substituting the values of $a_{1}, a_{2}, a_{3}$, and $a_{4}$ into Formulas (A48)and(A49), the optimal strategies $\left(E_{L}, E_{R}\right)$ and $\left(E_{F}, E_{I}\right)$ of local enterprises in developing countries along the Belt and Road Initiative and Chinese enterprises can be obtained, respectively. Then substitute $\left(E_{L}, E_{R}\right)$ and $\left(E_{F}, E_{I}\right)$ into Formula (5) and Formula (6), respectively, then:

$$
\begin{gathered}
\left\{\begin{array}{c}
H_{A}^{\prime}(t)=Q^{N}-\delta H_{A}(t) \\
H_{A}(0)=H_{A}
\end{array}\right. \\
\left\{\begin{array}{c}
H_{B}^{\prime}(t)=Z^{N}-\theta H_{B}(t) \\
H_{B}(0)=H_{B}
\end{array}\right.
\end{gathered}
$$

Among them, $Q^{N}=\alpha_{F} E_{F}^{N}+\alpha_{L} E_{L}^{N}, Z^{N}=\beta_{F} E_{I}^{N}+\beta_{R} E_{R}^{N}$. By solving Formulas (A57) and (A58), the expressions of carbon emission reduction $H_{A}(t)$ of the final product and influence $H_{B}(t)$ of the final product in the host country can be obtained as follows:

$H_{A}^{N}=\frac{Q^{N}}{\delta}+\left(H_{A}-\frac{Q^{N}}{\delta}\right) e^{-\delta * t}$

$H_{B}^{N}=\frac{Z^{N}}{\theta}+\left(H_{B}-\frac{Z^{N}}{\theta}\right) e^{-\theta^{*} \mathrm{t}}$

Substituting the values of $a_{1}, a_{2}, a_{3}, a_{4}, b_{1}$, and $b_{2}$ into Formulas (A59) and (A60), the optimal return functions $V_{L}\left(H_{A}, H_{B}\right)$ and $V_{F}\left(H_{A}, H_{B}\right)$ local enterprises along the Belt and Road Initiative and Chinese enterprises can be obtained as follows:

$$
\begin{aligned}
V_{L}^{N}= & \frac{\mu \omega}{\rho+\delta} H_{A}^{N}+\frac{\mu \eta}{\rho+\theta} H_{B}^{N}+\frac{\mu^{2}\left[\gamma_{L}(\rho+\delta)+\alpha_{L} \omega\right]^{2}}{2 \rho k_{L}(\rho+\delta)^{2}}+\frac{\left(\mu \eta \beta_{R}\right)^{2}}{2 \rho k_{R}(\rho+\theta)^{2}} \\
& +\frac{\mu(1-\mu)\left[\gamma_{F}(\rho+\delta)+\alpha_{F} \omega\right]^{2}}{\rho k_{F}(\rho+\delta)^{2}}+\frac{\mu(1-\mu)\left(\eta \beta_{F}\right)^{2}}{\rho k_{I}(\rho+\theta)^{2}} \\
V_{F}^{N}= & \frac{(1-\mu) \omega}{\rho+\delta} H_{A}^{N}+\frac{(1-\mu) \eta}{\rho+\theta} H_{B}^{N}+\frac{(1-\mu)^{2}\left[\gamma_{F}(\rho+\delta)+\alpha_{F} \omega\right]^{2}}{2 \rho k_{F}(\rho+\delta)^{2}} \\
& +\frac{\left[(1-\mu)\left(\eta \beta_{R}\right)\right]^{2}}{2 \rho k_{I}(\rho+\theta)^{2}}+\frac{\mu(1-\mu)\left[\gamma_{L}(\rho+\delta)+\alpha_{L} \omega\right]^{2}}{\rho k_{L}(\rho+\delta)^{2}} \\
& +\frac{\mu(1-\mu)\left(\eta \beta_{R}\right)^{2}}{\rho k_{R}(\rho+\theta)^{2}}
\end{aligned}
$$


Therefore, the optimal benefit function $V\left(H_{A}, H_{B}\right)$ of cooperative emission reduction between local enterprises along the Belt and Road Initiative and Chinese enterprises under this model can be obtained as follows:

$$
\begin{aligned}
V^{N}= & \frac{\omega}{\rho+\delta} H_{A}^{N}+\frac{\eta}{\rho+\theta} H_{B}^{N}+\frac{\mu(2-\mu)\left[\gamma_{L}(\rho+\delta)+\alpha_{L} \omega\right]^{2}}{2 \rho k_{L}(\rho+\delta)^{2}} \\
& +\frac{\mu(2-\mu)\left(\eta \beta_{R}\right)^{2}}{2 \rho k_{R}(\rho+\theta)^{2}}+\frac{(1+\mu)(1-\mu)\left[\gamma_{F}(\rho+\delta)+\alpha_{F} \omega\right]^{2}}{2 \rho k_{F}(\rho+\delta)^{2}} \\
& +\frac{(1+\mu)(1-\mu)\left(\eta \beta_{F}\right)^{2}}{2 \rho k_{I}(\rho+\theta)^{2}}
\end{aligned}
$$

\section{Appendix 2. Proof of Proposition 2}

Firstly, we assumed that the bounded income function $V_{i}\left(H_{A}\right.$, $\left.H_{B}\right)(i \in\{L, F\})$ of local enterprises along the Belt and Road Initiative and Chinese enterprises in continuously differentiable satisfies HJB equation for all $H_{A} \geq 0$ and $H_{B} \geq 0$, and adopts reverse induction method to solve the optimal decision-making problem of local enterprises along the "the Belt and Road Initiative," which can be obtained as follows:

$$
\begin{aligned}
& \rho V_{L}\left(H_{A}, H_{B}\right)=\max _{E_{L}: E_{R}}\left\{\mu\left(\gamma_{F} E_{F}+\gamma_{L} E_{L}+\omega H_{A}+\eta H_{B}\right)\right. \\
& \quad-\frac{1}{2} k_{L}\left(1-\lambda_{L}\right) E_{L}^{2}-\frac{1}{2} k_{R}\left(1-\lambda_{R}\right) E_{R}^{2}+\frac{\partial V_{L}}{\partial H_{A}}\left(\alpha_{L} E_{L}+\alpha_{F} E_{F}-\delta H_{A}\right) \\
& \left.\quad+\frac{\partial V_{L}}{\partial H_{B}}\left(\beta_{F} E_{I}+\beta_{R} E_{R}-\theta H_{B}\right)\right\}
\end{aligned}
$$

Equation (A64) is a concave function of $\left(E_{L}, E_{R}\right)$; let the right end of formula (A64) finds the first partial derivatives of $E_{L}$ and $E_{R}$, respectively, and makes them equal to 0 . Then the optimal strategies of local enterprises in developing countries along the Belt and Road Initiative can be obtained as follows:

$\left(E_{L}, E_{R}\right)=\left(\frac{\mu \gamma_{L}+\alpha_{L} \frac{\partial V_{L}}{\partial H_{A}}}{k_{L}\left(1-\lambda_{L}\right)}, \frac{\beta_{R} \frac{\partial V_{L}}{\partial H_{B}}}{k_{R}\left(1-\lambda_{R}\right)}\right)$
As a rational decision-maker, Chinese enterprises can accurately predict the best strategic choice of local enterprises in developing countries along the Belt and Road Initiative. Therefore, Chinese enterprises will decide their optimal strategy and subsidy ratio according to the reaction function formula (A65) of local enterprises in developing countries along the Belt and Road Initiative. Therefore, to continue to solve the optimal decision-making problem of Chinese enterprises, we can get:

$$
\begin{aligned}
\rho V_{F}\left(H_{A}, H_{B}\right)= & \max _{E_{F} ; E_{I}}\left\{(1-\mu)\left(\gamma_{F} E_{F}+\gamma_{L} E_{L}+\omega H_{A}+\eta H_{B}\right)\right. \\
& -\frac{1}{2} k_{F} E_{F}^{2}-\frac{1}{2} k_{I} E_{I}^{2}-\frac{1}{2} \lambda_{L} k_{L} E_{L}^{2}-\frac{1}{2} \lambda_{R} k_{R} E_{R}^{2} \\
& +\frac{\partial V_{F}}{\partial H_{A}}\left(\alpha_{F} E_{F}+\alpha_{L} E_{L}-\delta H_{A}\right) \\
& \left.+\frac{\partial V_{F}}{\partial H_{B}}\left(\beta_{F} E_{I}+\beta_{R} E_{R}-\theta H_{B}\right)\right\}
\end{aligned}
$$

Substitute Formula (A65)into Formula (A66), and then make the right end of Formula (A66) find the first-order partial derivatives of $\left(E_{F}, E_{I}\right), \lambda_{L}$, and $\lambda_{R}$ and make them equal to 0 ; the optimal strategy of Chinese enterprises can be obtained as follows:

$\left(E_{F}, E_{I}\right)=\left(\frac{(1-\mu) \gamma_{F}+\frac{\partial V_{F}}{\partial H_{A}} \alpha_{F}}{k_{F}}, \frac{\frac{\partial V_{F}}{\partial H_{B}} \beta_{F}}{k_{I}}\right)$

$\lambda_{M}=\frac{2 \frac{\partial V_{F}}{\partial H_{A}} \alpha_{L}-\frac{\partial V_{L}}{\partial H_{A}} \alpha_{L}+\gamma_{L}(2-3 \mu)}{2 \frac{\partial V_{F}}{\partial H_{A}} \alpha_{L}+\frac{\partial V_{L}}{\partial H_{A}} \alpha_{L}+\gamma_{L}(2-\mu)}$

$\lambda_{R}=\frac{2 \frac{\partial V_{F}}{\partial H_{B}}-\frac{\partial V_{L}}{\partial H_{B}}}{2 \frac{\partial V_{F}}{\partial H_{B}}+\frac{\partial V_{L}}{\partial H_{B}}}$

Substituting $\left(E_{L}, E_{R}\right),\left(E_{F}, E_{I}\right), \lambda_{L}$, and $\lambda_{R}$ into Eqs. (A64) and (A66), we get

$$
\begin{gathered}
\rho V_{L}\left(H_{A}, H_{B}\right)=\left(\mu \omega-\frac{\partial V_{L}}{\partial H_{A}} \delta\right) H_{A}+\left(\mu \eta-\frac{\partial V_{L}}{\partial H_{B}} \theta\right) H_{B}+\frac{\left(\frac{\partial V_{L}}{\partial H_{A}} \alpha_{F}+\mu \gamma_{F}\right)\left[(1-\mu) \gamma_{F}+\frac{\partial V_{F}}{\partial H_{A}} \alpha_{F}\right]}{k_{F}} \\
-\frac{\beta_{F}^{2} \frac{\partial V_{F}}{\partial H_{B}} \frac{\partial V_{L}}{\partial H_{B}}}{k_{I}}+\frac{\left(\frac{\partial V_{L}}{\partial H_{A}} \alpha_{L}+\mu \gamma_{L}\right)\left[2 \frac{\partial V_{F}}{\partial H_{A}} \alpha_{L}+\frac{\partial V_{L}}{\partial H_{A}} \alpha_{M}+(2-\mu) \gamma_{L}\right]}{4 k_{L}}+\frac{\beta_{R}^{2}\left(2 \frac{\partial V_{F}}{\partial H_{B}}+\frac{\partial V_{L}}{\partial H_{B}}\right) \frac{\partial V_{L}}{\partial H_{B}}}{4 k_{R}}
\end{gathered}
$$




$$
\begin{gathered}
\rho V_{F}\left(H_{A}, H_{B}\right)=\left(\omega(1-\mu)-\frac{\partial V_{F}}{\partial H_{A}} \delta\right) H_{A}+\left(\eta(1-\mu)-\frac{\partial V_{F}}{\partial H_{B}} \theta\right) H_{B}+\frac{\left[(1-\mu) \gamma_{F}+\frac{\partial V_{F}}{\partial H_{A}} \alpha_{F}\right]^{2}}{2 k_{F}} \\
+\frac{\left(\frac{\partial V_{F}}{\partial H_{B}} \beta_{F}\right)^{2}}{2 k_{I}}+\frac{\left[2 \frac{\partial V_{F}}{\partial H_{A}} \alpha_{L}+\frac{\partial V_{L}}{\partial H_{A}} \alpha_{L}+\gamma_{L}(2-\mu)\right]}{8 k_{L}}+\frac{\beta_{R}^{2}\left(2 \frac{\partial V_{F}}{\partial H_{B}}+\frac{\partial V_{L}}{\partial H_{B}}\right)^{2}}{8 k_{R}}
\end{gathered}
$$

From the forms of Formulas (A70) and (A71), it can be inferred that their solutions are binary linear functions about $H_{A}$ and $H_{B}$, respectively, so that:

$V_{L}\left(H_{A}, H_{B}\right)=m_{1} H_{A}+m_{2} H_{B}+n_{1}$

$V_{F}\left(H_{A}, H_{B}\right)=m_{3} H_{A}+m_{4} H_{B}+n_{2}$

In which $m_{1}, m_{2}, m_{3}, m_{4}, n_{1}$, and $n_{2}$ are constants. Substituting $V_{L}\left(H_{A}, H_{B}\right), V_{F}\left(H_{A}, H_{B}\right)$, and their first partial derivatives into Formulas (A70) and (A71), we can get:

$$
\begin{aligned}
\rho V_{L}( & \left.m_{1} H_{A}+m_{2} H_{B}+n_{1}\right)=\left(\mu \omega-m_{1} \delta\right) H_{A}+\left(\mu \eta-m_{2} \theta\right) H_{B} \\
& +\frac{\left(\mu \gamma_{F}+m_{1} \alpha_{F}\right)\left[(1-\mu) \gamma_{F}+m_{3} \alpha_{F}\right]}{k_{F}}-\frac{\beta_{F}^{2} m_{2} m_{4}}{k_{I}} \\
& +\frac{\left(m_{1} \alpha_{L}+\mu \gamma_{L}\right)\left[2 m_{3} \alpha_{L}+m_{1} \alpha_{L}+\gamma_{L}(2-\mu)\right]}{4 k_{L}} \\
& +\frac{m_{2}\left(2 m_{4}+m_{2}\right) \beta_{R}^{2}}{4 k_{R}}
\end{aligned}
$$

$$
\begin{aligned}
& \rho V_{F}\left(m_{3} H_{A}+m_{4} H_{B}+n_{2}\right)=\left[(1-\mu) \omega-m_{3} \delta\right] H_{A}+\left[(1-\mu) \eta-m_{4} \theta\right] H_{B} \\
& +\frac{\left[(1-\mu) \gamma_{F}+m_{3} \alpha_{F}\right]^{2}}{2 k_{F}}-\frac{\left(\beta_{F} m_{4}\right)^{2}}{2 k_{I}}+\frac{\left[2 m_{3} \alpha_{L}+m_{1} \alpha_{L}+\gamma_{L}(2-\mu)\right]}{8 k_{L}} \\
& +\frac{\left(2 m_{4}+m_{2}\right)^{2} \beta_{R}^{2}}{8 k_{R}}
\end{aligned}
$$

As both Formulas (A74) and (A75) should satisfy $H_{A} \geq 0$ and $H_{B} \geq 0$, the parameter values of $m_{1}, m_{2}, m_{3}, m_{4}, n_{1}$, and $n_{2}$ can be obtained as follows:

$$
\left\{\begin{array}{c}
m_{1}=\frac{\mu \omega}{\rho+\delta} \\
m_{2}=\frac{\mu \eta}{\rho+\theta} \\
n_{1}=\frac{\mu(1-\mu)\left[\gamma_{F}(\rho+\delta)+\omega \alpha_{F}\right]^{2}}{\rho k_{F}(\rho+\delta)^{2}}+\frac{\mu(1-\mu)\left(\eta \beta_{F}\right)^{2}}{\rho k_{I}(\rho+\theta)^{2}}+\frac{\mu(2-\mu)\left[\gamma_{L}(\rho+\delta)+\omega \alpha_{L}\right]^{2}}{4 \rho k_{L}(\rho+\delta)^{2}}+\frac{\mu(2-\mu)\left(\eta \beta_{R}\right)^{2}}{4 \rho k_{R}(\rho+\theta)^{2}} \\
m_{3}=\frac{(1-\mu) \omega}{\rho+\delta} \\
m_{4}=\frac{(1-\mu) \eta}{\rho+\theta} \\
n_{2}=\frac{(1-\mu)^{2}\left[\gamma_{F}(\rho+\delta)+\omega \alpha_{F}\right]^{2}}{2 \rho k_{F}(\rho+\delta)^{2}}+\frac{(1-\mu)^{2}\left(\eta \beta_{F}\right)^{2}}{2 \rho k_{I}(\rho+\theta)^{2}}+\frac{(2-\mu)^{2}\left[\gamma_{L}(\rho+\delta)+\omega \alpha_{L}\right]^{2}}{8 \rho k_{L}(\rho+\delta)^{2}}+\frac{(2-\mu)^{2}\left(\eta \beta_{R}\right)^{2}}{8 \rho k_{R}(\rho+\theta)^{2}}
\end{array}\right.
$$

Substituting the values of $m_{1}, m_{2}, m_{3}, m_{4}, n_{1}$, and $n_{2}$ into Formulas (A65), (A67), (A68), and (A69), we can obtain the optimal strategies of local enterprises along the Belt and Road Initiative and Chinese enterprises, as well as the optimal subsidy factors $\lambda_{L}$ and $\lambda_{R}$ of Chinese enterprises. And then substituting them into Formula (5) and Formula (6), then we can get:

$$
\left\{\begin{array}{c}
H_{A}^{\prime}(t)=Q^{S}-\delta H_{A}(t) \\
H_{A}(0)=H_{A}
\end{array}\right.
$$

$\left\{\begin{array}{c}H_{B}^{\prime}(t)=Z^{S}-\theta H_{B}(t) \\ H_{B}(0)=H_{B}\end{array}\right.$

Among them, $\quad Q^{S}=\alpha_{F} E_{F}^{S}+\alpha_{L} E_{L}^{S} \quad$ and $Z^{S}=\beta_{F} E_{I}^{S}+\beta_{R} E_{R}^{S}$. By solving Formulas (A77) and (A78), we can obtain the expressions of carbon emission reduction $H_{A}(t)$ of the final product and influence $H_{B}(t)$ of the final product in the host country, which are respectively: 
$H_{A}^{S}=\frac{Q^{S}}{\delta}+\left(H_{A}-\frac{Q^{S}}{\delta}\right) e^{-\delta * t}$

$H_{B}^{S}=\frac{Z^{S}}{\theta}+\left(H_{B}-\frac{Z^{S}}{\theta}\right) e^{-\theta * t}$

Substituting the values of $m_{1}, m_{2}, m_{3}, m_{4}, n_{1}$ and $n_{2}$ into Formulas (A79) and (A80), the optimal return functions $V_{L}\left(H_{A}, H_{B}\right)$ and $V_{F}\left(H_{A}, H_{B}\right)$ of local enterprises along the Belt and Road Initiative and Chinese enterprises can be obtained, respectively, as follows:

$$
\begin{aligned}
V_{L}^{S}= & \frac{\mu \omega}{\rho+\delta} H_{A}^{S}+\frac{\mu \eta}{\rho+\theta} H_{B}^{S}+\frac{\mu(1-\mu)\left[\gamma_{F}(\rho+\delta)+\alpha_{F} \omega\right]^{2}}{\rho k_{F}(\rho+\delta)^{2}} \\
& +\frac{\mu(1-\mu)\left(\eta \beta_{F}\right)^{2}}{\rho k_{I}(\rho+\theta)^{2}}+\frac{\mu(2-\mu)\left[\gamma_{L}(\rho+\delta)+\alpha_{L} \omega\right]^{2}}{4 \rho k_{L}(\rho+\delta)^{2}} \\
& +\frac{\mu(2-\mu)\left(\eta \beta_{R}\right)^{2}}{4 \rho k_{R}(\rho+\theta)^{2}}
\end{aligned}
$$

$$
\begin{aligned}
V_{F}^{S}= & \frac{(1-\mu) \omega}{\rho+\delta} H_{A}^{S}+\frac{(1-\mu) \eta}{\rho+\theta} H_{B}^{S}+\frac{(1-\mu)^{2}\left[\gamma_{F}(\rho+\delta)+\alpha_{F} \omega\right]^{2}}{2 \rho k_{F}(\rho+\delta)^{2}} \\
& +\frac{(1-\mu)^{2}\left(\eta \beta_{F}\right)^{2}}{2 \rho k_{I}(\rho+\theta)^{2}}+\frac{(2-\mu)^{2}\left[\gamma_{L}(\rho+\delta)+\alpha_{L} \omega\right]^{2}}{8 \rho k_{L}(\rho+\delta)^{2}} \\
& +\frac{(2-\mu)^{2}\left(\eta \beta_{R}\right)^{2}}{8 \rho k_{R}(\rho+\theta)^{2}}
\end{aligned}
$$

Therefore, the optimal benefit function $V\left(H_{A}, H_{B}\right)$ of cooperative emission reduction between Chinese enterprises and local enterprises in developing countries along the Belt and Road Initiative under this model can be obtained as follows:

$$
\begin{aligned}
V^{S}= & \frac{\omega}{\rho+\delta} H_{A}^{S}+\frac{\eta}{\rho+\theta} H_{B}^{S}+\frac{(2+\mu)(2-\mu)\left[\gamma_{L}(\rho+\delta)+\alpha_{L} \omega\right]^{2}}{8 \rho k_{L}(\rho+\delta)^{2}} \\
& +\frac{(2+\mu)(2-\mu)\left(\eta \beta_{R}\right)^{2}}{8 \rho k_{R}(\rho+\theta)^{2}}+\frac{(1+\mu)(1-\mu)\left[\gamma_{F}(\rho+\delta)+\alpha_{F} \omega\right]^{2}}{2 \rho k_{F}(\rho+\delta)^{2}} \\
& +\frac{(1+\mu)(1-\mu)\left(\eta \beta_{F}\right)^{2}}{2 \rho k_{I}(\rho+\theta)^{2}}
\end{aligned}
$$

\section{Appendix 3. Proof of Proposition 3}

Under this circumstance, Chinese enterprises and local enterprises in developing countries along the Belt and Road Initiative jointly improve the efficiency and quality of carbon emission reduction through cooperation. As an organic whole, both parties will take the maximization of overall benefits as the goal and jointly determine the optimal decision of both parties. At this point, the objective function of the system is:

$$
\begin{gathered}
\Pi=\Pi_{L}+\Pi_{F}=\int_{0}^{\infty} e^{-\rho t}\left[\mu_{F}\left(\gamma_{F} E_{F}(t)+\gamma_{L} E_{L}(t)+w H_{A}(t)+\eta H_{B}(t)\right)-\frac{1}{2} k_{F} E_{F}^{2}(t)\right. \\
\left.-\frac{1}{2} k_{l} E_{I}^{2}(t)-\frac{1}{2} k_{L} E_{L}^{2}(t)-\frac{1}{2} k_{R} E_{R}^{2}(t)\right] d t
\end{gathered}
$$

Assuming that the tripartite cooperation carbon emission reduction system has a bounded benefit function $V\left(H_{A}, H_{B}\right)$, which satisfies $\mathrm{HJB}$ equation for all $H_{A} \geq 0$ and $H_{B} \geq 0$, we can get:

$$
\begin{aligned}
\rho V\left(H_{A}, H_{B}\right)= & \max _{E_{R} ; E_{L} ; E_{F}: E_{I}}\left\{\left(\gamma_{F} E_{F}+\gamma_{L} E_{L}+\omega H_{A}+\eta H_{B}\right)\right. \\
& -\frac{1}{2} k_{F} E_{F}^{2}-\frac{1}{2} k_{I} E_{I}^{2}-\frac{1}{2} k_{L} E_{L}^{2}-\frac{1}{2} k_{R} E_{R}^{2} \\
& +\frac{\partial V}{\partial H_{A}}\left(\alpha_{F} E_{F}+\alpha_{L} E_{L}-\delta H_{A}\right) \\
& \left.+\frac{\partial V}{\partial H_{B}}\left(\beta_{F} E_{I}+\beta_{R} E_{R}-\theta H_{B}\right)\right\}
\end{aligned}
$$

Equation (A85) is a concave function of $\left(E_{L}, E_{R}\right)$ and $\left(E_{F}\right.$, $\left.E_{I}\right)$. According to the first-order conditions, the optimal strategy of Chinese enterprises and local enterprises along the Belt and Road Initiative can be obtained as follows:

$\left(E_{L}, E_{R}\right)=\left(\frac{\gamma_{L}+\frac{\partial V}{\partial H_{A}} \alpha_{L}}{k_{L}}, \frac{\frac{\partial V}{\partial H_{B}} \beta_{R}}{k_{R}}\right)$

$\left(E_{F}, E_{I}\right)=\left(\frac{\gamma_{F}+\frac{\partial V}{\partial H_{A}} \alpha_{F}}{k_{F}}, \frac{\frac{\partial V}{\partial H_{B}} \beta_{F}}{k_{I}}\right)$

Substituting $\left(E_{L}, E_{R}\right)$ and $\left(E_{F}, E_{I}\right)$ into formula (A85) and simplify it, we can obtain:

$$
\begin{gathered}
\rho V\left(H_{A}, H_{B}\right)=\left(\omega-\frac{\partial V}{\partial H_{A}} \delta\right) H_{A}+\left(\eta-\frac{\partial V}{\partial H_{B}} \theta\right) H_{B} \\
+\frac{\left(\gamma_{F}+\frac{\partial V}{\partial H_{A}} \alpha_{F}\right)^{2}}{2 k_{F}}+\frac{\left(\gamma_{L}+\frac{\partial V}{\partial H_{A}} \alpha_{L}\right)^{2}}{2 k_{L}}+\frac{\left(\frac{\partial V}{\partial H_{B}} \beta_{F}\right)^{2}}{2 k_{I}}+\frac{\left(\frac{\partial V}{\partial H_{B}} \beta_{R}\right)^{2}}{2 k_{R}}
\end{gathered}
$$

By observing the form of formula (A88), we can infer that its solution is a binary linear function about $H_{A}$ and $H_{B}$, thus making:

$V\left(H_{A}, H_{B}\right)=h_{1} H_{A}+h_{2} H_{B}+h_{3}$

In which $h_{1}, h_{2}$, and $h_{3}$ are constants, substituting $V\left(H_{A}\right.$, $H_{B}$ ) and its first-order partial derivatives into Formula (A88), we can get: 


$$
\begin{gathered}
\rho\left(h_{1} H_{A}+h_{2} H_{B}+h_{3}\right)=\left(\omega-h_{1} \delta\right) H_{A}+\left(\eta-h_{2} \theta\right) H_{B} \\
+\frac{\left(\gamma_{F}+h_{1} \alpha_{F}\right)^{2}}{2 k_{F}}+\frac{\left(\gamma_{L}+h_{1} \alpha_{L}\right)^{2}}{2 k_{L}}+\frac{\left(h_{2} \beta_{F}\right)^{2}}{2 k_{I}}+\frac{\left(h_{2} \beta_{R}\right)^{2}}{2 k_{R}}
\end{gathered}
$$

Equation (A90) should satisfy all $H_{A} \geq 0$ and $H_{B} \geq 0$, so the parameter values of $h_{1}, h_{2}$, and $h_{3}$ can be obtained as follows:

$$
\left\{\begin{array}{c}
h_{1}=\frac{\omega}{\rho+\delta} \\
h_{2}=\frac{\eta}{\rho+\theta} \\
h_{3}=\frac{\left[\gamma_{F}(\rho+\delta)+\omega \alpha_{F}\right]^{2}}{2 \rho k_{F}(\rho+\delta)^{2}}+\frac{\left[\gamma_{L}(\rho+\delta)+\omega \alpha_{L}\right]^{2}}{2 \rho k_{L}(\rho+\delta)^{2}}+\frac{\left(\eta \beta_{F}\right)^{2}}{2 \rho k_{I}(\rho+\theta)^{2}}+\frac{\left(\eta \beta_{R}\right)^{2}}{2 \rho k_{R}(\rho+\theta)^{2}}
\end{array}\right.
$$

Substituting the values of $h_{1}$ and $h_{2}$ into Formulas (A86) and (A87), the optimal strategies $\left(E_{L}, E_{R}\right)$ and $\left(E_{F}, E_{I}\right)$ of Chinese enterprises and local enterprises in developing countries along the Belt and Road Initiative are obtained in turn. And then substituting them into Formula (5) and Formula (6), then we can get:

$$
\begin{aligned}
& \left\{\begin{array}{c}
H_{A}^{\prime}(t)=Q^{C}-\delta H_{A}(t) \\
H_{A}(0)=H_{A}
\end{array}\right. \\
& \left\{\begin{array}{c}
H_{B}^{\prime}(t)=Z^{C}-\theta H_{B}(t) \\
H_{B}(0)=H_{B}
\end{array}\right.
\end{aligned}
$$

Among them, $Q^{C}=\alpha_{F} E_{F}^{C}+\alpha_{L} E_{L}^{C}$ and $Z^{C}=\beta_{F} E_{I}^{C}+\beta_{R} E_{R}^{C}$. By solving Formulas (A92) and (A93), we can obtain the expressions of carbon emission reduction $H_{A}(t)$ of the final product and influence $H_{B}(t)$ of the final product in the host country, which are respectively:

$H_{A}^{C}=\frac{Q^{C}}{\delta}+\left(H_{A}-\frac{Q^{C}}{\delta}\right) e^{-\delta^{*} t}$

$H_{B}^{C}=\frac{Z^{C}}{\theta}+\left(H_{B}-\frac{Z^{C}}{\theta}\right) e^{-\theta^{* t}}$

Substituting the values of $h_{1}$ and $h_{2}$ into formula (A89), we can obtain the optimal benefit function $V\left(H_{A}, H_{B}\right)$ of cooperative emission reduction between Chinese enterprises and local enterprises in developing countries along the Belt and Road Initiative:

$$
\begin{aligned}
V^{C}= & \frac{\omega}{\rho+\delta} H_{A}+\frac{\eta}{\rho+\theta} H_{B}+\frac{\left[\gamma_{F}(\rho+\delta)+\omega \alpha_{F}\right]^{2}}{2 \rho k_{F}(\rho+\delta)^{2}} \\
& +\frac{\left[\gamma_{L}(\rho+\delta)+\omega \alpha_{L}\right]^{2}}{2 \rho k_{L}(\rho+\delta)^{2}}+\frac{\left(\eta \beta_{F}\right)^{2}}{2 \rho k_{I}(\rho+\theta)^{2}}+\frac{\left(\eta \beta_{R}\right)^{2}}{2 \rho k_{R}(\rho+\theta)^{2}}
\end{aligned}
$$

Acknowledgements The authors are grateful to the Editor and anonymous referees for their valuable comments and suggestions.
Authors' contributions Xiangyu Mao: Writing - original draft-software, and methodology. Ying Wang: Funding acquisition, project administration, and conceptualization

Funding This work was supported by the National Natural Science Foundation of China [grant numbers 71873064] and the Humanities and Social Science Research General Project of the Ministry of Education [grant numbers 18YJA790085].

Data availability The datasets used and/or analyzed during the current study are available from the corresponding author on reasonable request.

\section{Declarations}

Ethics approval and consent to participate Not applicable

Consent for publication Not applicable

Competing interests The authors declare that they have no known competing financial interests or personal relationships that could have appeared to influence the work reported in this paper.

\section{References}

Andornino GB (2017) The Belt and Road Initiative in China's Emerging Grand Strategy of Connective Leadership. China World Econ 25(5): 4-22. https://doi.org/10.1111/cwe.12211

Anwar A, Sarwar S, Amin W, Arshed N (2019) Agricultural practices and quality of environment: evidence for global perspective. Environ Sci Pollut Res 26:15617-15630. https://doi.org/10.1007/ s11356-019-04957-x

Chen Z, Yan T, Zhao W, Ni G (2021) Capacity utilization loss of the Belt and Road countries incorporating carbon emission reduction and the impacts of China's OFDI. J Clean Prod 280:123926. https://doi.org/ 10.1016/j.jclepro.2020.123926

Cheng LK (2016) Three questions on China's "Belt and Road Initiative." China Economic Review 40:309-313. https://doi.org/10.1016/j. chieco.2016.07.008

Dargusch P (2017) China must lead on emissions trading. Science 357(6356):1106-1107. https://doi.org/10.1126/science.aap7960

Ding J, Chen W, Wang W (2020) Computers \& Industrial Engineering Production and carbon emission reduction decisions for remanufacturing firms under carbon tax and take-back legislation. Comput Ind Eng 143(November 2019):106419. https://doi.org/10. 1016/j.cie.2020.106419

Fan JL, Da YB, Wan SL, Zhang M, Cao Z, Wang Y, Zhang X (2019) Determinants of carbon emissions in 'Belt and Road initiative' countries: A production technology perspective. Appl Energy 239(October 2018):268-279. https://doi.org/10.1016/j.apenergy. 2019.01.201

Farooq MU, Shahzad U, Sarwar S, Zaijun L (2019) The impact of carbon emission and forest activities on health outcomes: Empirical evidence from China. Environ Sci Pollut Res 26(13):12894-12906. https://doi.org/10.1007/s11356-019-04779-x

Han L, Han B, Shi X, Su B, Lv X, Lei X (2018) Energy efficiency convergence across countries in the context of China's Belt and Road initiative. Appl Energy 213(September 2017):112-122. https://doi.org/10.1016/j.apenergy.2018.01.030

Han M, Lao J, Yao Q, Zhang B, Meng J (2020) Carbon inequality and economic development across the Belt and Road regions. J Environ Manag 262(February):110250. https://doi.org/10.1016/j.jenvman. 2020.110250 
Haque M, Paul SK, Sarker R, Essam D (2020) Managing decentralized supply chain using bilevel with Nash game approach. J Clean Prod 266:121865. https://doi.org/10.1016/j.jclepro.2020.121865

Khan MK, Sandano IA, Pratt CB, Farid T (2018) China's Belt and Road Initiative: A global model for an evolving approach to sustainable regional development. Sustainability (Switzerland) 10(11):1-20. https://doi.org/10.3390/su10114234

Li B, Gasser T, Ciais P, Piao S, Tao S, Balkanski Y, Hauglustaine D, Boisier JP, Chen Z, Huang M, Zhaoxin Li L, Li Y, Liu H, Liu J, Peng S, Shen Z, Sun Z, Wang R, Wang T et al (2016) The contribution of China's emissions to global climate forcing. Nature 531(7594):357-361. https://doi.org/10.1038/nature17165

Li H, Wang C, Shang M, Ou W, Qin X (2019) Cooperative decision in a closed-loop supply chain considering carbon emission reduction and low-carbon promotion. Environ Prog Sustain Energy 38(1):143153. https://doi.org/10.1002/ep.13092

Li E, Lu M, Chen Y (2020) Analysis of China's importance in "belt and road initiative" trade based on a gravity model. Sustainability (Switzerland) 12(17):1-20. https://doi.org/10.3390/SU12176808

Liu Y, Hao Y (2018) The dynamic links between CO2 emissions, energy consumption and economic development in the countries along "the Belt and Road". Sci Total Environ 645:674-683. https://doi.org/10. 1016/j.scitotenv.2018.07.062

Liu H, Wang Y, Jiang J, Wu P (2020) How green is the "Belt and Road Initiative"? - Evidence from Chinese OFDI in the energy sector. Energy Policy 145(July):111709. https://doi.org/10.1016/j.enpol. 2020.111709

Liu H, Fan X, Lim G (2021a) Singapore engages the belt and road initiative: perceptions, policies, and institutions. Singap Econ Rev 66(1): 219-241. https://doi.org/10.1142/S0217590820410015

Liu L, Zhang Z, Wang Z (2021b) Two-sided matching and game on investing in carbon emission reduction technology under a capand-trade system. J Clean Prod 282(xxxx):124436. https://doi.org/ 10.1016/j.jclepro.2020.124436

Ma J, Hou Y, Yang W, Tian Y (2020) A time-based pricing game in a competitive vehicle market regarding the intervention of carbon emission reduction. Energy Policy 142(September 2019):111440. https://doi.org/10.1016/j.enpol.2020.111440

Mahadevan R, Sun Y (2020) Effects of foreign direct investment on carbon emissions: Evidence from China and its Belt and Road countries. J Environ Manag 276(April):111321. https://doi.org/10.1016/ j.jenvman.2020.111321

Muhammad S, Long X, Salman M, Dauda L (2020) Effect of urbanization and international trade on $\mathrm{CO} 2$ emissions across 65 belt and road initiative countries. Energy 196:117102. https://doi.org/10. 1016/j.energy.2020.117102

Qi S, Peng H, Zhang X, Tan X (2019) Is energy efficiency of Belt and Road Initiative countries catching up or falling behind? Evidence from a panel quantile regression approach. Appl Energy 253(July): 113581. https://doi.org/10.1016/j.apenergy.2019.113581

Qian YJ, Ding W, Wu WP, Bandikhuu A, Damdindorj T, Nyamdorj T, Bold B, Dorjsuren T, Sumiya G, Guan YY, Zhou XN, Li SZ, Don Eliseo LP (2019) A path to cooperation between China and Mongolia towards the control of echinococcosis under the Belt and Road Initiative. Acta Trop 195(April):62-67. https://doi.org/10.1016/j.actatropica.2019.04.022

Qin J, Han Y, Wei G, Xia L (2020) The value of advance payment financing to carbon emission reduction and production in a supply chain with game theory analysis. Int J Prod Res 58(1):200-219. https://doi.org/10.1080/00207543.2019.1671626
Rauf A, Liu X, Amin W, Ozturk I, Rehman OU, Sarwar S (2018) Energy and ecological sustainability: Challenges and panoramas in belt and road initiative countries. Sustainability (Switzerland) 10(8):1-21. https://doi.org/10.3390/su10082743

Sarwar S (2019) Role of urban income, industrial carbon treatment plants and forests to control the carbon emission in China. Environ Sci Pollut Res 26(16):16652-16661. https://doi.org/10.1007/s11356019-04854-3

Sarwar S, Alsaggaf MI (2019) Role of urbanization and urban income in carbon emissions: Regional analysis of China. Appl Ecol Environ Res 17(5):10303-10311. https://doi.org/10.15666/aeer/1705 1030310311

Sarwar S, Alsaggaf MI (2021) The role of governance indicators to minimize the carbon emission: a study of Saudi Arabia. Manag Environ Qual Int J 32(5):970-988. https://doi.org/10.1108/MEQ-11-20200275

Sarwar S, Alsaggaf MI, Tingqiu C (2019) Nexus Among Economic Growth, Education, Health, and Environment: Dynamic Analysis of World-Level Data. Front Public Health 7(October):1-15. https://doi.org/10.3389/fpubh.2019.00307

Shan H, Yang J, Wei G (2019) Industrial symbiosis systems: Promoting carbon emission reduction activities. Int J Environ Res Public Health 16(7):1-23. https://doi.org/10.3390/ijerph16071093

Sun L, Cao X, Alharthi M, Zhang J, Taghizadeh-Hesary F, Mohsin M (2020) Carbon emission transfer strategies in supply chain with lag time of emission reduction technologies and low-carbon preference of consumers. J Clean Prod 264:121664. https://doi.org/10.1016/j. jclepro.2020.121664

Tao Y, Liang H, Celia MA (2020) Electric power development associated with the Belt and Road Initiative and its carbon emissions implications. Appl Energy 267(February):114784. https://doi.org/10.1016/ j.apenergy.2020.114784

Varrall M (2013) Chinese views on China's role in international development assistance. Pac Aff 86(2):233-255. https://doi.org/10.5509/ 2013862233

Wang M, Li Y, Li M, Shi W, Quan S (2019) Will carbon tax affect the strategy and performance of low-carbon technology sharing between enterprises? J Clean Prod 210:724-737. https://doi.org/10.1016/j. jclepro.2018.10.321

Wu P, Song Y, Zhu J, Chang R (2019) Analyzing the influence factors of the carbon emissions from China's building and construction industry from 2000 to 2015. J Clean Prod 221(2019):552-566. https://doi. org/10.1016/j.jclepro.2019.02.200

Wu J, Kaixuan G, Zhu Q, Zheng W, Chang Y (n.d.) An Analysis of the Emission Reduction Targets of "Belt and Road " Countries Based on Their NDC Reports. May 2017, 1-19

Xia L, Bai Y, Ghose S, Qin J (2020) Differential game analysis of carbon emissions reduction and promotion in a sustainable supply chain considering social preferences. Ann Oper Res 25. https://doi.org/ 10.1007/s10479-020-03838-8

Yang B, Swe T, Chen Y, Zeng C, Shu H, Li X, Yu T, Zhang X, Sun L (2021) Energy cooperation between Myanmar and China under One Belt One Road: Current state, challenges and perspectives. Energy 215:119130. https://doi.org/10.1016/j.energy.2020.119130

Yilmaz S, Changming L (2020) Remaking Eurasia: the Belt and Road Initiative and China-Russia strategic partnership. Asia Europe Journal 18(3):259-280. https://doi.org/10.1007/s10308-01900547-1

Zhang YJ, Jin YL, Shen B (2020) Measuring the Energy Saving and CO2 Emissions Reduction Potential Under China's Belt and Road 
Initiative. Comput Econ 55(4):1095-1116. https://doi.org/10.1007/ s10614-018-9839-0

Zhao Y, Liu X, Wang S, Ge Y (2019) Energy relations between China and the countries along the Belt and Road: An analysis of the distribution of energy resources and interdependence relationships. Renew Sust Energ Rev 107(March):133-144. https://doi.org/10. 1016/j.rser.2019.03.007

Zhen W, Lin Z (2017) Giving Play to the Leading Role of Energy Cooperation in the Belt and Road Initiative. China Oil Gas 2:17-24
Zu Y, Chen L, Fan Y (2018) Research on low-carbon strategies in supply chain with environmental regulations based on differential game. $\mathrm{J}$ Clean Prod 177(December 2015):527-546. https://doi.org/10.1016/ j.jclepro.2017.12.220

Publisher's note Springer Nature remains neutral with regard to jurisdictional claims in published maps and institutional affiliations. 